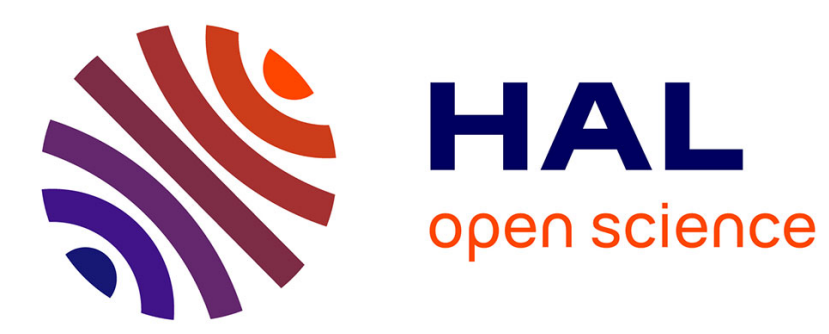

\title{
Predictive analysis of combined burner parameter effects on oxy-fuel flames
}

\author{
T. Boushaki, S. Guessasma, J.C. Sautet
}

\section{To cite this version:}

T. Boushaki, S. Guessasma, J.C. Sautet. Predictive analysis of combined burner parameter effects on oxy-fuel flames. Applied Thermal Engineering, 2010, 31 (2-3), pp.202. 10.1016/j.applthermaleng.2010.08.034 . hal-00692333

\section{HAL Id: hal-00692333 \\ https://hal.science/hal-00692333}

Submitted on 30 Apr 2012

HAL is a multi-disciplinary open access archive for the deposit and dissemination of scientific research documents, whether they are published or not. The documents may come from teaching and research institutions in France or abroad, or from public or private research centers.
L'archive ouverte pluridisciplinaire HAL, est destinée au dépôt et à la diffusion de documents scientifiques de niveau recherche, publiés ou non, émanant des établissements d'enseignement et de recherche français ou étrangers, des laboratoires publics ou privés. 


\section{Accepted Manuscript}

Title: Predictive analysis of combined burner parameter effects on oxy-fuel flames

Authors: T. Boushaki, S. Guessasma, J.C. Sautet

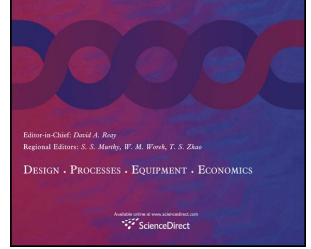

PII:

S1359-4311(10)00377-7

DOI:

10.1016/j.applthermaleng.2010.08.034

Reference:

ATE 3227

To appear in: Applied Thermal Engineering

Received Date: 24 April 2009

Revised Date: 29 July 2010

Accepted Date: 31 August 2010

Please cite this article as: T. Boushaki, S. Guessasma, J.C. Sautet. Predictive analysis of combined burner parameter effects on oxy-fuel flames, Applied Thermal Engineering (2010), doi: 10.1016/ j.applthermaleng.2010.08.034

This is a PDF file of an unedited manuscript that has been accepted for publication. As a service to our customers we are providing this early version of the manuscript. The manuscript will undergo copyediting, typesetting, and review of the resulting proof before it is published in its final form. Please note that during the production process errors may be discovered which could affect the content, and all legal disclaimers that apply to the journal pertain. 


\title{
Predictive analysis of combined burner parameter effects on oxy-fuel flames
}

\author{
T. Boushaki ${ }^{1,2}$, S. Guessasma ${ }^{3 *}$, J.C. Sautet ${ }^{1}$ \\ ${ }^{1}$ CNRS UMR 6614 - CORIA, University of Rouen, 76801 Saint Etienne du Rouvray cedex, \\ France \\ 2 IMFT UMR 5502 CNRS-INP-UPS, 1 Allée du Professeur Camille Soula \\ 31400 Toulouse, France \\ ${ }^{3}$ INRA - BIA, rue de la géraudière 44316 Nantes, France \\ *corresponding author \\ sofiane.guessasma@nantes.inra.fr \\ Tel. (0) 33240675036 \\ Fax. (0) 33240675167
}

\begin{abstract}
The present paper aims at studying the influence of burner parameters with a separated jet configuration, namely nozzles diameters and separation distance between the jets, on the flame characteristics (lift-off positions of flame and flame length). The experimental layout considers the use of $\mathrm{OH}$-chemilumenescence to measure the flame characteristics for different combinations of processing conditions. The predictive analysis is based on a neural computation that considers the correlations between the inputs and the outputs of a combustion system using a configuration of separated jet. The predictive analysis show that a good agreement is found between numerical and experimental results in the case where the predictions are within the process window. The exploration of other process parameter combinations beyond that window gives less convincing results. This is mainly attributed to the fact that steady state characteristics are predicted numerically whereas it is expected experimentally that some of burner parameter combinations can lead to an increase of the parameters characterizing the flame.
\end{abstract}

Keywords: Oxy-fuel combustion; Separated jet burners; lifted flame; neural computation. 


\section{Introduction}

Oxy-fuel burners are widely used in high-temperature industrial furnaces to improve productivity and fuel efficiency, to reduce emissions of pollutants, and to eliminate the capital and maintenance costs of an air preheater. Indeed, the substitute oxygen by air provides a high flame temperature, a less consumption of fuel and a low NOx production since we eliminate the nitrogen of air $[1,2]$. This makes it possible to have a better thermal efficiency and a better stabilization of flame. Furthermore, the use of oxy-combustion in separated jet burners open interesting possibilities in the pollutant reduction such the NOx and the modularity of flame properties (stabilization, topology, flame length, etc.) [3, 4]. For separated jet burners, the principle is based on the geometrical separation of its nozzles. This design gives a high dilution of the reactants by the combustion products, a large and plate flame and a homogeneous temperature in all volume of flame [4,5].

Flames from burner with multiple jets have many practical situations. Several studies have been published on the structure and development of non-reacting multiple jets [6-9]. However, the studies of multiple jet flames are mostly limited, for example, flame developing in still air without confinement [10] or in a wind tunnel with cross flow [11]. Recently, Lee et al. (2004) [12] studied the blowout limit considering the interaction of multiple nonpremixed jet flames and giving a number of variables such as distance between the jets, the number of jets and their arrangements.

The burner configuration used in this work is composed of three round jets, one central jet of natural gas and two lateral jets of pure oxygen. The power of burner is $25 \mathrm{~kW}$ and the flames develop inside combustion chamber with 1-m high. The $\mathrm{OH}$ chemiluminescence technique has been used to indicate the instantaneous flame reaction zone and thereby characterize features of the stabilization region. The lift-off positions and the flame lengths for several configurations of burner are measured. 
Various parameters govern the flow from burner with multiple jets such as the number of jets, the form of nozzles, the spacing between the jets, the exit velocities, etc. Consequently, these geometrical and dynamical parameters of burner have important effects on the behaviour of flame. Considering the number of parameters, many configurations of burner are possible however it is experimentally difficult to study all possible cases. In a previous paper [4], several configurations have been tested experimentally to highlight the influence of tubes diameters, distance between the jets and the deflection of jets on the characteristics of the flame. Based on these experimental results we study in the present paper the behaviour of stabilization point (height and radius) as well as the flame length using a numerical method based on the artificial neural network (ANN). The methodology is an advanced statistical of data analysis [13]. It is particularly used when the correlations between the inputs and outputs of a given problem are difficult to capture using standard fitting routines. Typical examples of complex correlations can be found in the case of input interdependencies, several outputs attached to a set of inputs, a large number of parameter combinations, among others. The neural computation was already applied to different situations related to engineering processes $[14,15]$. In this paper, we are concerned by the study of the interactions between the burner parameters and their influence on the flame characteristics in a set-up that uses separate jets. This work is actually an extension of a previously published experimental study [4] and it aims at predicting the flame behaviour within and outside the operating window. The operating window represents here the range of the burner parameters used in the experimental investigation. We have used neural computation instead of standard fitting tools because of the nonlinear correlation between burner characteristics and the burner parameters as pointed out by several authors [16-17]. In addition, simple preliminary analysis of the experimental data detailed hereafter have shown a significant burner parameters interdependencies [3-4]. 


\section{Experimental layout}

The experimental system consisted of a burner and operating conditions, a furnace, and $\mathrm{OH}$ Chemiluminescence setup. Fig. 1 shows a schematic diagram of the separated-jet burner apparatus. The burner is composed of three round tubes, one central of natural gas and two side tubes of pure oxygen. The fuel is a mixture of natural gas $\left(85.2 \% \mathrm{CH}_{4}, 9.1 \% \mathrm{C}_{2} \mathrm{H}_{6}\right.$, $2.44 \% \mathrm{C}_{3} \mathrm{H}_{8}, 1.97 \% \mathrm{~N}_{2}, 0.75 \% \mathrm{CO}_{2}$, plus traces of higher hydrocarbon species) with a density $\rho_{\mathrm{ng}}=0.83 \mathrm{~kg} \cdot \mathrm{m}^{-3}$ and a net calorific value $(\mathrm{NCV})$ is $45 \mathrm{MJ} / \mathrm{kg}$. Fuel and oxidizer flow rates are constant for all experiments to ensure constant power flames of $25 \mathrm{~kW}$ $\left(\dot{\mathrm{M}}_{\mathrm{ng}}=556 \cdot 10^{-3} \mathrm{~kg} \cdot \mathrm{s}^{-1}, \dot{\mathrm{M}}_{\mathrm{ox}}=1964 \cdot 10^{-3} \mathrm{~kg} \cdot \mathrm{s}^{-1}\right)$. The internal diameters $\left(\mathrm{d}_{\mathrm{ng}}\right.$ and $\left.\mathrm{d}_{\mathrm{ox}}\right)$ range from 4 to $10 \mathrm{~mm}$, and the separation distance between the jets $(\mathrm{S})$ varies from 7 to $30 \mathrm{~mm}$. Table 1 summarizes the operating conditions of burner parameters including the central and side jet characteristics (diameter, exit velocity and Reynolds number). The burner is located on the bottom wall of the furnace, which is a 1-m-high vertical tunnel with square cross section $(60 \times$ $60 \mathrm{~cm}$ ). The lateral walls are refractory lined on the inside and water cooled on the outside. Optical access is provided through quartz windows.

$\mathrm{OH}^{*}$ chemiluminescence technique is used (Fig. 2) to describe the flame front and therefore to measure liftoff positions and flame lengths. The radical $\mathrm{OH}^{*}$ characterizes the reaction zone, and is present in sufficiently high proportion giving a good quality signal, in particular for the oxy-fuel combustion $[4,18]$. However, the chemiluminescence of other radicals $\left(\mathrm{CH}^{*}\right.$ at $430.5 \mathrm{~nm}$ or $\mathrm{C}_{2} *$ at $516.5 \mathrm{~nm}$ ) representative of the reaction zone can also be considered, although the use of an interferential filter is necessary, inducing a signal with a very low intensity. Furthermore, the presence of pure oxygen as oxidizer leads to a higher rate of $\mathrm{OH}$ radical compared to other radicals such as $\mathrm{C}_{2}$ and $\mathrm{CH}$. The radical $\mathrm{OH}^{*}$ is located in the reaction zone where it has been created. $\mathrm{OH}^{*}$ is not very sensitive to the turbulent convection, 
as well as its life time in an electronic excited state is very short $(\sim 1 \mu \mathrm{m})$, allowing an accurate location where the radical is created. Emission of $\mathrm{OH}^{*}$ radical is located in the wavelength range from 280 to $310 \mathrm{~nm}$. The molecule excited $\mathrm{OH}^{*}$ is formed by the following reactions [19]:

$$
\begin{array}{lll}
\mathrm{H}+\mathrm{O}+\mathrm{M} & \leftrightarrows & \mathrm{OH}^{*}+\mathrm{M} \\
\mathrm{H}+\mathrm{OH}+\mathrm{OH} & \leftrightarrows & \mathrm{OH}^{*}+\mathrm{H}_{2} \mathrm{O} \\
\mathrm{CH}+\mathrm{O}_{2} & \leftrightarrows & \mathrm{OH}^{*}+\mathrm{CO}
\end{array}
$$

The $\mathrm{OH}^{*}$ formation implies radicals as $\mathrm{H}, \mathrm{O}$ and $\mathrm{CH}$, witch are formed only in the reaction zone.

The flame images have been acquired by collecting the instantaneous $\mathrm{OH}^{*}$ of the main band $(0,0)$ at $306.4 \mathrm{~nm}$ on a Princeton Instrument ICCD camera, with an 85-mm UV Nikkor lens (f/5.6). The camera is operated in a 512×512-pixel format with 16 -bit dynamic range. The $\mathrm{OH}^{*}$ emission band has been filtered with a SCHOTT UG11 band-pass filter which has a transmittance coefficient greater than 0.1 between 275 and $375 \mathrm{~nm}$. Sets of 400 images (exposure time $90 \mu \mathrm{s}$ ) were accumulated for each operating condition at different heights of flame.

To extract the lift-off heights and the flame lengths, classical image processing (binarization, average, rms, thresholding) was used on all the images for each configuration. To determine the lift-off position of flame, it is necessary to perform a binarization then a detection of contour. The choice of threshold of binarization is delicate since we have to eliminate the noise from the images without affecting the signal. The method used here consists in locating the region of interest where the flame is stabilized and then to make a profile of the signal along the axis of object. Threshold value is taken at the inflection point of the intensity profile. Lift-off height is determined as the closest point to the burner where the signal appears. Fig. 3 shows an example of image processing for $\mathrm{OH}$ chemiluminescence in the stabilization region. 
The flame length estimation is based on the visualization at the flame top. Fig. 4a shows an example of instantaneous images of the flame top. After binarization, the flame length can be measured for each configuration as shown in Fig. $4 \mathrm{~b}$. To do so, the pixel corresponding to the end of flame (highest position) is extracted and the average of these maximum values on all acquired images is calculated, following the expression:

$$
\mathrm{L}_{\mathrm{f}}=\mathrm{Z}_{0}+\frac{\sum_{\mathrm{i}=1}^{\mathrm{i}=\mathrm{n}} \mathrm{Z}_{\mathrm{i}}}{\mathrm{n}}
$$

where $\mathrm{Z}_{0}$ is the exit burner - base flame distance, $\mathrm{Zi}$ is the height of the flame in the image $\mathrm{i}$ and $\mathrm{n}$ is the number of instantaneous images used for the processing (Fig. 4b).

The experimental results related to the flame characteristics for several configurations of burner are summarized in Table 2. The lift-off positions (vertical position, $\mathrm{Z}_{\mathrm{lo}}$ and horizontal position, $\left.\mathrm{X}_{\mathrm{lo}}\right)$ and the flame lengths $\mathrm{L}_{\mathrm{f}}$ are given as a function of nozzle diameters $\left(\mathrm{d}_{\mathrm{ng}}\right.$ and $d_{o x}$ ) and the separation distance between the jets (S). The horizontal position of flame lift-off (or radius) has a zero value at the centre of the central jet of the natural gas. 


\section{Modelling technique}

Neural computation requires several steps to allow the predictions of the correlations between the input and output of the present problem. The basic mechanism behind ANN is the neuron activity. The neuron is a mathematical processing unit that receives an input (a number), transforms it (by simple mathematical operations) and forward it to other neurons.

Details about the methodology can be found in $[13,20]$. In the following, we will stick to a concise description of the technique.

\section{Step1: definition of the input/output sets}

Three burner parameters (the internal diameters $\mathrm{d}_{\mathrm{ng}}, \mathrm{d}_{\mathrm{ox}}$ and the separation distance between the jets $S$ ) are attributed each one neuron. This set of neurons represents the input pattern. The output pattern represents the flame characteristics (the vertical and horizontal lift-off positions $\mathrm{Z}_{\mathrm{lo}}, \mathrm{X}_{\mathrm{lo}}$ and the flame lengths $\mathrm{L}_{\mathrm{f}}$ ). All variables are expressed in a dimensionless form. Indeed, since the parameter range can influence the quality of the predictions, all variables are expressed in the range $0-1$, using the upper and lower limits available for each variable. Such pre-processing assumes the following conversion scheme, which is detailed in previous studies

$$
\mathrm{y}_{\mathrm{i}}=\frac{\mathrm{x}_{\mathrm{i}}-\mathrm{x}_{\min }}{\mathrm{x}_{\max }-\mathrm{x}_{\min }}
$$

where $\mathrm{y}_{\mathrm{i}}$ is the dimensionless form of the variable $\mathrm{x}_{\mathrm{i}} \cdot \mathrm{x}_{\min }$ and $\mathrm{x}_{\max }$ represent the window range of variable $\mathrm{x}_{\mathrm{i}}$. These limits are summarized in Table 3 for all studied parameters.

Each neuron is connected the other neurons following a feed-forward scheme. This writes $\mathrm{I}_{\mathrm{i}}=\mathrm{W}_{\mathrm{ij}} \mathrm{O}_{\mathrm{j}}$

where $\mathrm{I}_{\mathrm{i}}$ is the input of neuron $\mathrm{i}$ belonging to the forward layer, $\mathrm{Oj}$ is the output of a given neuron $\mathrm{j}$ from the backward layer $\mathrm{W}_{\mathrm{ij}}$ is the weight parameter that relates neurons $\mathrm{i}$ and $\mathrm{j}$. A typical sketch of the neuron connectivity can be found in [13] 
The output of a given neuron is related to its input using the expression [21]

$$
\mathrm{O}_{\mathrm{i}}=\frac{1}{1+\exp \left(-\mathrm{I}_{\mathrm{i}}\right)}
$$

where the sigmoid function is used to nonlinearly transform the input of each neuron in the network structure. The output is thus bounded between 0 and +1 .

\section{Step2: building the database}

As the number of experimental sets is limited (29 experiments as shown in Table 2), small ANN structures are used. A typical structure comprises the input and output patterns plus hidden units (neurons) organised in intermediate layers. The more units in the hidden layers, the more experimental sets needed for the optimisation of the ANN structure. Thus, it is decided to keep one intermediate layer for which the number of neurons is varied between 1 and 6. Following the correlation between weight population and database size, we are slightly below the lower bound when 6 neurons are used in the hidden layer (see for example [13]). We vary the neuron number between the abovementioned bounds to demonstrate where the robustness of neural network is applicable. We know that a unique neuron in the hidden layer is insufficient to give reliable prediction and we know also that 6 neurons is larger than the weight population. Thus, optimal neural network have to be searched between these bounds.

The database is organised in two main categories: training and test categories. The training set data are picked out randomly and varied between $0 \%$ to $100 \%$, where the percentage is expressed with respect to the whole database.

\section{Step3: performing the analysis}

Training category is used to tune the neuron connections, i.e., weights [20]. In the test procedure, experimental sets are used without correcting any weight. The convergence of the procedure is obtained if the error evolution of the training and test steps stabilise. The procedure is robust if these quantities are close to each other and small enough. The error is obtained by comparing the experimental and numerical response for a given input condition. 
Two main convergence criteria are studied: the average and maximum errors calculated with respect to the submitted cases. The average quantity is expressed as a mean square error.

Step4: solving the problem of equivalent ANN structures

The ANN structures (obtained by varying the neuron number) are classified based on the smallest training and testing errors and also on the basis of the lowest percentage of the data in the training set used for the optimisation. 


\section{Results and discussion}

Fig. 5 shows a typical optimisation procedure of the ANN structure. The convergence criteria are two average and two maximum errors. The evolution of training errors as function of iteration level up to 1000 itrs well depicts the stabilisation of the convergence criteria beyond 300 cycles (Fig. 5a). We have selected a small iteration number compared to what is reported in the literature because we have used an efficient training algorithm that can lead to significant overtraining. The final iteration number is large enough to obtain a steady state asymptotic error evolution (significant changes are within the first 300 iterations). The maximum iteration number is lower than 10000 to avoid overtraining. Fig. 5a well shows that overtraining is not attained since the maximum error is higher than the average error. When increasing the number of neurons from 1 to 6 , the final training error decreases. Such a decrease is explained by the increase of the weight number (increase of connections between neurons). This has the consequence to give more variables to the system to find the best weight configuration with respect to a given set of submitted samples. However, when the weight number is too large, the prediction beyond the operating window becomes less evident to trust because a proper prediction requires more experimental sets. In our case, we do not need to have a large neuron number as suggested in Fig. 5a because even in the worst case (one unique neuron in the hidden layer), the maximum error is still less than $5 \%$. Fig. $5 \mathrm{~b}$ shows the evolution of the test criterion for a training database size of $70 \%$. Convergence of the criterion is obtained irrespective of the neuron number. In particular, with two neurons in the hidden layer, the test errors are the smallest ones. The difference between the maximum and the average error seems more significant compared to the training procedure.

Fig. 6 shows the training and test error maps after an optimisation procedure performed on the output $\mathrm{Z}_{\mathrm{lo}}$. Note that these maps correspond to the error values at the final iteration level 
where convergence is assumed. Both criteria training and test errors exhibit steady state evolution whatever is the difference between the criteria. The error domain is twodimensional with the horizontal axis representing the number of neurons $(\mathrm{NN})$ and the vertical one being the percentage of training samples (Tr). Robustness of the neural network can be thus determined. A robust net structure corresponds to a smallest difference between training and test errors combined to the smallest training set and larges test set. The average training error varies between 0.003 and 0.017 in the case of the training procedure (Figure 6a). The error domain is nearly homogeneous. It shows that the training error is significantly dependent on the percentage of training samples rather than on the number of neurons. This result can be inferred to the fact that the large number of iterations (1000 in the present case) is sufficient to enforce the convergence whatever is the neuron number. It seems that at $\operatorname{Tr}=50 \%$, the error decreases with the decrease of neuron number. Two optimal configurations are found corresponding to $(\mathrm{NN}=2, \mathrm{Tr}=70 \%)$ and $(\mathrm{NN}=6, \mathrm{Tr}=50 \%)$.

In the case of test procedure, the predicted map contains discriminating information (Fig. 6b) as we can see clearly that the decrease of training samples (i.e., the decrease of test database size) predicts the minimum error. The influence of the neuron number is minor. Thus, it makes sense to choose the configuration ( $\mathrm{NN}=2, \mathrm{Tr}=70 \%)$ as being the optimal condition. Our selection is based on the fact with 2 neurons the weight population is reduced so that the predictions are more reliable. This situation is comparable to searching optimal function with few parameters to fit the experimental data. Of course, selecting the optimal neural structure based on a smaller training set would be also reasonable.

Fig. 7 compares the experimental and predicted responses at the final iteration level in the case of $Z_{10}$ and for two particular ANN structures. Both responses are expressed in reduced units. For both cases, the slope of the curve is close to unity with a satisfying correlation factor $\left(R^{2}>0.96\right)$. Since training and test data are different, we are certain that the causal 
correlations encoded in the ANN structure are well captured. Again, the slight deviation of the numerical results with regard to the experimental values attests that overtraining is not attained.

The result of the optimisation procedure described above is still valid for the two other outputs. In the following, the exploitation of the ANN predictions is detailed. This exploitation considers the optimal ANN structure for which the weight parameters are fixed. It considers also different combinations of input parameters varied in a continuous way and for which the outputs are calculated for each input combination.

Fig. 8a shows the effect of varying separation distance and the oxygen jet diameter on the value of lift-off height of flame for a given value of $d_{n g}$. $Z_{l_{0}}$ is found to be the highest one for a large $S$ and a small $d_{\text {ox }}$ values. The tendency seems to be polynomial rather than linear. The increase of S delays the mixing of reactants and consequently the combustion starts later at larger distances from burner. This obvious result is well reported in the literature [11-12]. The decrease of $d_{o x}$ leads to the increase of the oxygen jet velocity because a fixed flow rate is used. Thus, the flame base is moved far away from the nozzles exits [11, 22-25]. Fig. 8b shows the same evolution map for a larger $d_{n g}$ value. Despite the similar tendency obtained using the combination of $\mathrm{S}$ and $\mathrm{d}_{\mathrm{ox}}$ (i.e., the increase of $\mathrm{Z}_{\mathrm{lo}}$ is correlated to the increase of $\mathrm{S} / \mathrm{d}_{\mathrm{ox}}$ ), a smaller domain where this effect prevails is noticed. Indeed, as illustrated in Fig. 8b, the region below the solid line exhibits the smallest $\mathrm{Z}_{\mathrm{lo}}$ values. In fact, a small natural gas jet diameter increases the jet velocity because of the constant flow rate. Thus, when increasing $d_{n g}$, smaller $Z_{l o}$ values are expected for a given combination of $S$ and $d_{o x}$.

Fig. 8c depicts the effect of $S$ and $d_{n g}$ on $Z_{10}$ for a given value of $d_{o x}$. It is clearly shown here that a polynomial evolution is predicted in this case. $Z_{10}$ is found to increase with the increase of the ratio $\mathrm{S} / \mathrm{d}_{\mathrm{ng}}$. It can be demonstrated (all results are not shown here) that any of the 
combinations $\left(S, d_{o x}\right),\left(S, d_{n g}\right)$ or $\left(d_{o x}, d_{n g}\right)$ leads firmly to a polynomial correlation where $\mathrm{Z}_{\mathrm{lo}}$ increases with the increase of $\mathrm{S} / \mathrm{d}_{\mathrm{ox}}, \mathrm{S} / \mathrm{d}_{\mathrm{ng}}$ or $1 /\left(\mathrm{d}_{\mathrm{ng}} \mathrm{x} \mathrm{d}_{\mathrm{ox}}\right)$.

The effect of the burner parameters on horizontal position of flame base is shown in Fig. 9. When combining $S$ and $d_{o x}$ for a fixed value of $d_{n g}$, it is predicted that $X_{1 o}$ increases nonlinearly only with the increase of $S$ for any particular value of $d_{\text {ox }}$ (Fig. 9a). In fact, the horizontal position of the stabilisation point is fully dependent on the spacing between the jets due to geometrical considerations [4]. When increasing $d_{n g}$, no major change in $X_{l o}$ is observed either in magnitude nor in trend, which means that the unique control parameter is the spacing between the jets.

The combined effect of separation distance between the jets and the natural gas jet diameter on horizontal position of the stabilisation point is shown in Fig. 9b. The trend is different from the first case. Despite that $S$ is the first control parameter ( $\mathrm{X}_{\mathrm{lo}}$ increases when $\mathrm{S}$ increases), $d_{\text {ng }}$ plays a secondary role as predicted in Fig. $9 \mathrm{~b}$ (slightly higher levels of $\mathrm{X}_{\text {lo }}$ are predicted when increasing $d_{n g}$ ). In Fig. $9 c$ is presented the evolution of $X_{l o}$ as function of $d_{n g}$ and $d_{o x}$. Again, the effect of $d_{n g}$ is predominant compared to $d_{o x}$. The higher is $d_{n g}$ value, the larger is $\mathrm{X}_{\mathrm{lo}}$ response. This last trend confirms the previous results (Figs. 9a, 9b) in the sense that a classification of the influential effects can be deduced based on the analysis of all maps shown in Fig. 9. In fact, $S$ is the major control factor, $d_{n g}$ is the intermediate one and $d_{o x}$ has the smallest effect. The interaction effects are more subtle except when combining $S$ and $d_{n g}$. The analysis of the third output (the flame length) as function of studied parameters reveals the following ideas summarized in Fig. 10. When combining $S$ and $d_{\text {ox }}$ (Fig. 10a), it is predicted that the evolution of $\mathrm{L}_{\mathrm{f}}$ is positively correlated to the evolution of the product $\mathrm{S} x$ $\mathrm{d}_{\mathrm{ox}}$. This actually represents the unique combination of burner parameters where an 
interaction effect is highlighted. Indeed, when comparing this result to that corresponding for example to the combination ( $\left.\mathrm{S}, \mathrm{d}_{\mathrm{ng}}\right)$, it is found that only $\mathrm{S}$ has an effect on $\mathrm{L}_{\mathrm{f}}$ (Fig. 10b). This is also confirmed by the last trend (Fig. 10c) where the increase of $\mathrm{L}_{\mathrm{f}}$ is only attributed to the increase of $d_{o x}$. The prevailing effect of $S$ can be deduced from the mixing process of natural gas and oxygen for which the increase of $\mathrm{S}$ means a delay of the combustion start and an increase of the flame length [3].

In order to quantify all the previously mentioned correlations, fitting routine is applied on the predicted data. Table 4 summarizes the coefficients of a simple regression applied for all studied outputs

$$
y_{j}=a+\sum_{i=1}^{3} x_{i}+\sum_{i=1}^{3} x_{i}{ }^{2}+\sum_{i=1}^{3} \sum_{j>i}^{3} x_{i} x_{j}\left(1-\delta_{i j}\right)+x_{1} x_{2} x_{3}
$$

where $a$ is a constant value, $y_{j}$ is one of the output responses $\left(\mathrm{L}_{\mathrm{f}}, \mathrm{X}_{\mathrm{lo}}, \mathrm{Z}_{\mathrm{lo}}\right)$ and $\mathrm{x}_{\mathrm{i}}$ is one of the inputs $\left(\mathrm{S}, \mathrm{d}_{\mathrm{ox}}, \mathrm{d}_{\mathrm{ng}}\right), \delta$ is the Kronecker operator. 


\section{Conclusions}

The combined effect of burner parameters ( $S$ : separation distance between the jets, $d_{o x}$ and $d_{n g}$ : the jet diameters of oxygen and natural gas, respectively) on the studied flame characteristics suggests the following correlations:

- Lift-off height of flame is dependent on all burner parameter interactions in the sense that larger heights are proportional to single terms: $-8\left(d_{n g}+d_{o x}+0.03 S\right)$, quadratic terms $0.03\left(\mathrm{~d}_{\mathrm{ng}}{ }^{2}+\mathrm{d}_{\mathrm{ox}}{ }^{2}+0.5 \mathrm{~S}^{2}\right)$, simple interactions $0.5\left(\mathrm{~d}_{\mathrm{ng}} \mathrm{xd}_{\mathrm{ox}}+0.3 \mathrm{~S}\left(\mathrm{~d}_{\mathrm{ng}} \mathrm{xd}_{\mathrm{ox}}\right)\right)$ and all terms interaction $-0.016\left(\mathrm{~d}_{\mathrm{ox}} \mathrm{Sd}_{\mathrm{ng}}\right)$.

- The horizontal position of the flame lift-off is dependent on a unique burner parameter interaction $0.01\left(\mathrm{Sd}_{\mathrm{ng}}\right)$. If we exclude the former interaction term, a simple linear correlation $\left(\mathrm{R}^{2}=0.92\right)$ is sufficient to represent truly the correlations. This correlation highlights the prevailing role of $S$ and $d_{n g}$ compared to $d_{o x}: X_{10} \propto 0.3\left(S+d_{n g}\right.$ $\left.0.06 d_{\text {ox }}\right)$.

- The flame length is predicted to depend positively on all parameters. Combining $\mathrm{S}$ and $d_{\text {ox }}$ allows better results (in this case, the interaction term is 0.64). S and $d_{\text {ox }}$ represent here the most influential parameters to vary $\mathrm{L}_{\mathrm{f}}$. 


\section{References}

[1] A. Ivernel, P. Vernotte, Revue Générale de Thermique 210 (1979) 375-391.

[2] C.E. Baukal, B. Gebhart, Int. J. Heat Mass Tran. 40(11) (1997) 2539-2547.

[3] J.C. Sautet, T. Boushaki, L. Salentey, B. Labegorre, Combustion Sci. Technol. 178 (2006) 2075-2096.

[4] T. Boushaki, J-C. Sautet, L. Salentey, B. Labegorre, Int. Communication Heat Mass Transfer 34 (2007) 8-18.

[5] T. Boushaki, J-C. Sautet, Exp Fluids 48 (2010) 1095-1108.

[6] A. Krothapalli, D. Bagadanoff, K. Karamchetti, AIAA journal 18 (8) (1980) 945-950.

[7] S. Raghunatan, I.M. Reid, AIAA journal 19 (1980) 124-127.

[8] I. Yimer, H.A. Becker, E.W. Grandmaison, A.I.C.H.E Journal 74 (1996) 840-851.

[9] A. K. Moawad, N. Rajaratnam, S.J. Stanley, J. hydraulic research 39 (2) (2001) 163-168.

[10] A.O.P. Leite, M.A. Ferreira, J.A. Carvalho, Int. Comm. Heat Mass Transfer 23 (7) (1996) 959-970.

[11] R. Menon, S.R. Gollahali, Combust. Sci. Technol. 60 (1998) 375-389.

[12] B.J. Lee, J.S. Kim, S. Lee, Combustion Sci. Technol. 176 (2004) 481-497.

[13] S. Guessasma, G. Montavon and C. Coddet, Comput. Mat. Sci. 29 (3) (2004), 315-333.

[14] H. Deng, S. Guessasma, D. Benkrid, G. Montavon, H. Liao, S. Abouddi, C. Coddet, Numerical Heat Transfer, Part A 47 (6) (2005) 593-607.

[15] H. Fall, S. Guessasma, W. Sharon, Engineering Structures, 28 (2006) 1787-1794.

[16] B . Lenze, ME. Milano, R . Günther, Combust Sci Tech 11 (1975) 1-8.

[17] C.E. Baukal, Industrial Burners Handbook, CRC Press, 2003.

[18] M. DiTaranto, J.C. Sautet, J.M. Samaniego, Experiments in Fluids, 30 (2001) 253-261.

[19] D.S. Dandy, S.R.Vosen, Combustion Science and Technology, 82 (1992) 131-150. 
[20] S. Guessasma, Z. Salhi, G. Montavon, P. Gougeon and C. Coddet, Mat. Sci. Eng. B 110 (3) (2004) 285-295.

[21] T. Sahraoui, S. Guessasma, N Fenineche, G. Montavon, C. Coddet, Mat. Letters, 58(5) (2004) 654-660.

[22] G.T. Kalghatgi, Combustion Sci. Technol. 41 (1984) 17-29.

[23] L. Muniz, M.G. Mungal, Combustion and Flame 111 (1997) 16-31.

[24] R.W. Schefer, M. Namazian, J. Kelly, Proc. Int. $22^{\text {th }}$ Symposium on Combustion/The Combustion Institute, Seattle, USA, (1988) 833-842.

[25] A. Cessou, C. Maurey and D. Stepowski, Combustion and Flame 137 (4) (2004) 458477. 


\section{Figure captions}

Fig. 1. Schematic diagram of separated-jet burner.

Fig. 2. Schematic diagram of the Chemiluminescence setup.

Fig. 3. Example of image processing of the lift-off zone of a flame issued from an oxy-fuel burner with separated jets. (a) Instantaneous image, (b) binarized image, (c) the average image of 400 instantaneous images, and (c) the average image of binarized images.

Fig. 4. (a) Examples of $\mathrm{OH}$ instantaneous images at the flame top and (b) their corresponding binarized image.

Fig. 5. Evolution of the average and maximum convergence criteria as function of iteration level for an increasing number of neurons in the hidden layer. Runs are performed in the case of $\mathrm{Z}_{\mathrm{lo}}$ output - training database $70 \%$.

Fig. 6. (a) training and (b) test error maps relative to the output $\mathrm{Z}_{\mathrm{lo}}$ as function of neuron number and ratio from the whole database of samples used for training.

Fig. 7. Comparing experimental and predicted $\mathrm{Z}_{\mathrm{lo}}$ for two neural nets (optimal condition $\mathrm{NN}=1, \mathrm{TR}=50 \%$ and none-optimized condition $\mathrm{NN}=6, \mathrm{TR}=100 \%$ ).

Fig. 8. Predicted maps of $\mathrm{Z}_{\mathrm{lo}}$ as function of studied parameters. (a) $\mathrm{d}_{\mathrm{ng}}=4$, (b) $\mathrm{d}_{\mathrm{ng}}=11$, (c) $\mathrm{d}_{\mathrm{ox}}=15$.

Fig. 9. Predicted maps of $X_{l o}$ as function of studied parameters (a) $d_{n g}=5.8$, (b) $d_{o x}=13$ (c) $S=26$.

Fig. 10. Predicted maps of $\mathrm{L}_{\mathrm{f}}$ as function of studied parameters. (a) $\mathrm{d}_{\mathrm{ng}}=5.8$, (b) $\mathrm{d}_{\mathrm{ox}}=8$ (c) $\mathrm{S}=17$. 


\section{List of Tables}

Table 1. Operating conditions of the burner parameters.

Table 2. Experimental database used to assess lift-off positions of flame $\left(Z_{10}\right.$ and $\left.X_{10}\right)$ and flame length $\left(L_{f}\right)$ as a function of nozzles diameters (for the natural-gas jet, $d_{n g}$ and the oxygen jet, $\mathrm{d}_{\mathrm{ox}}$ ) and the separation distance between the jets (S).

Table 3. Window range of the studied parameters.

Table 4. Regression coefficients based on ANN predicted results and using different approximations. 
Table 1. Operating conditions of the burner parameters.

\begin{tabular}{|c|c|c|c|c|c|}
\hline \multicolumn{3}{|c|}{ Central natural gas jet } & \multicolumn{3}{|c|}{ One lateral oxygen jet } \\
\hline $\mathrm{d}_{\mathrm{ng}}(\mathrm{mm})$ & $\mathrm{U}_{\mathrm{ng}}^{0}(\mathrm{~m} / \mathrm{s})$ & $\operatorname{Re}_{\mathrm{ng}}$ & $\mathrm{d}_{\mathrm{ox}}(\mathrm{mm})$ & $\mathrm{U}_{\mathrm{ox}}^{0}(\mathrm{~m} / \mathrm{s})$ & $\operatorname{Re}_{\text {ox }}$ \\
\hline \multirow{3}{*}{4} & \multirow{3}{*}{53.3} & \multirow{3}{*}{16152} & 6 & 25.4 & 10792 \\
\hline & & & 8 & 14.3 & 8101 \\
\hline & & & 10 & 9.1 & 6444 \\
\hline \multirow{3}{*}{6} & \multirow{3}{*}{23.6} & \multirow{3}{*}{10727} & 6 & 25.4 & 10792 \\
\hline & & & 8 & 14.3 & 8101 \\
\hline & & & 10 & 9.1 & 6444 \\
\hline \multirow{2}{*}{8} & \multirow{2}{*}{13.4} & \multirow{2}{*}{8121} & 6 & 25.4 & 10792 \\
\hline & & & 8 & 14.3 & 8101 \\
\hline
\end{tabular}


Table 2. Experimental database used to assess lift-off positions of flame $\left(Z_{10}\right.$ and $\left.X_{10}\right)$ and flame length $\left(L_{f}\right)$ as a function of nozzles diameters (for the natural-gas jet, $d_{n g}$ and the oxygen jet, $d_{o x}$ ) and the separation distance between the jets (S).

\begin{tabular}{|c|c|c|c|c|c|c|}
\hline \multirow{2}{*}{ Exp. \# } & \multicolumn{3}{|c|}{ Inputs } & \multicolumn{3}{|c|}{ Outputs } \\
\hline & $\mathrm{d}_{\mathrm{ng}}(\mathrm{mm})$ & $\mathrm{d}_{\mathrm{ox}}(\mathrm{mm})$ & $\mathrm{S}(\mathrm{mm})$ & $\mathrm{Z}_{\mathrm{lo}}(\mathrm{mm})$ & $\mathrm{X}_{\mathrm{lo}}(\mathrm{mm})$ & $\mathrm{L}_{\mathrm{f}}(\mathrm{mm})$ \\
\hline 1 & 4 & 6 & 7 & 56.14 & 3.31 & 463 \\
\hline 2 & 4 & 8 & 8 & 14.43 & 3.19 & 527 \\
\hline 3 & 4 & 8 & 12 & 44.27 & 4.91 & 568 \\
\hline 4 & 4 & 8 & 16 & 77.90 & 6.31 & - \\
\hline 5 & 4 & 10 & 9 & 10.54 & 3.26 & - \\
\hline 6 & 4 & 10 & 12 & 27.30 & 4.53 & - \\
\hline 7 & 4 & 10 & 16 & 39.96 & 5.83 & - \\
\hline 8 & 6 & 6 & 8 & 19.03 & 3.94 & 461 \\
\hline 9 & 6 & 6 & 12 & 46.08 & 6.55 & 520 \\
\hline 10 & 6 & 6 & 16 & 61.78 & 8.52 & 548 \\
\hline 11 & 6 & 6 & 20 & 74.71 & 10.47 & 593 \\
\hline 12 & 6 & 6 & 30 & 92.08 & 13.90 & \\
\hline 13 & 6 & 8 & 9 & 11.84 & 4.17 & 564 \\
\hline 14 & 6 & 8 & $12 y$ & 23.77 & 5.54 & 580 \\
\hline 15 & 6 & 8 & 16 & 38.39 & 7.36 & 611 \\
\hline 16 & 6 & 8 & 20 & 49.12 & 9.14 & 656 \\
\hline 17 & 6 & 8 & 30 & 75.16 & 12.38 & - \\
\hline 18 & 6 & 10 & 10 & - & - & - \\
\hline 19 & 6 & 10 & 12 & 18.35 & 5.41 & - \\
\hline 20 & 6 & 10 & 16 & 28.64 & 6.80 & - \\
\hline 21 & 6 & 10 & 20 & 43.34 & 8.53 & - \\
\hline 22 & 8 & 6 & 9 & 11.69 & 4.93 & 452 \\
\hline 23 & 8 & 6 & 12 & 16.62 & 6.64 & 517 \\
\hline 24 & 8 & 6 & 16 & 33.19 & 8.65 & 507 \\
\hline 25 & 8 & 6 & 20 & 47.48 & 11.19 & 592 \\
\hline 26 & 8 & 8 & 10 & - & - & 568 \\
\hline 27 & 8 & 8 & 12 & 17.48 & 6.00 & 582 \\
\hline 28 & 8 & 8 & 16 & 28.82 & 7.95 & 608 \\
\hline 29 & 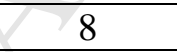 & 8 & 20 & 45.92 & 9.90 & 672 \\
\hline
\end{tabular}


Table 3. Window range of the studied parameters.

\begin{tabular}{|c|c|c|c|c|c|c|}
\hline \multirow{2}{*}{ Limit } & \multicolumn{3}{|c|}{ Inputs } & \multicolumn{3}{c|}{ Outputs } \\
\cline { 2 - 7 } & $\mathrm{d}_{\mathrm{ng}}(\mathrm{mm})$ & $\mathrm{d}_{\mathrm{ox}}(\mathrm{mm})$ & $\mathrm{S}(\mathrm{mm})$ & $\mathrm{Z}_{\mathrm{lo}}(\mathrm{mm})$ & $\mathrm{X}_{\mathrm{lo}}(\mathrm{mm})$ & $\mathrm{L}_{\mathrm{f}}(\mathrm{mm})$ \\
\hline $\mathrm{x}_{\text {Min }}$ & 4 & 4 & 7 & 0 & 0 & 0 \\
\hline $\mathrm{x}_{\max }$ & 20 & 20 & 50 & - & - & - \\
\hline
\end{tabular}


Table 4. Regression coefficients based on ANN predicted results and using different approximations.

\begin{tabular}{|c|c|c|c|c|c|c|c|c|c|c|c|c|}
\hline & $\mathrm{a}$ & $\mathrm{d}_{\mathrm{ox}}$ & $\mathrm{d}_{\mathrm{ng}}$ & S & $d_{o x}^{2}$ & $d_{n g}{ }^{2}$ & $\mathrm{~S}^{2}$ & $d_{n g} x d_{o x}$ & $\mathrm{~d}_{\mathrm{ox}} \mathrm{xS}$ & $\mathrm{d}_{\mathrm{ng}} \mathrm{xS}$ & $d_{n g} \times d_{o x} x S$ & $\mathrm{R}^{2}$ \\
\hline \multirow{4}{*}{$\mathrm{Z}_{\mathrm{lo}}$} & 109 & -8.1 & -8.3 & -0.26 & 0.029 & 0.033 & 0.014 & 0.515 & 0.143 & 0.138 & -0.016 & 0.92 \\
\hline & 43 & -2.6 & -2.8 & 2.0 & 0.03 & 0.03 & 0.01 & 0.06 & -0.05 & -0.05 & $\bar{c}$ & 0.89 \\
\hline & 69 & -3.3 & -3.6 & 0.82 & 0.03 & 0.03 & 0.01 & & & & 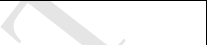 & 0.86 \\
\hline & 53 & -2.6 & -2.8 & 1.6 & & & & & & & 7 & 0.85 \\
\hline \multirow{4}{*}{$X_{10}$} & -4.4 & -0.13 & 0.67 & 0.68 & 0.0010 & -0.0031 & -0.0048 & 0.0040 & 0.0022 & -0.0092 & -0.0001 & 0.99 \\
\hline & -4.7 & -0.11 & 0.69 & 0.69 & 0.0010 & -0.0030 & -0.0048 & 0.0017 & 0.0012 & -0.0102 & $y$ & 0.99 \\
\hline & -2.1 & -0.04 & 0.44 & 0.59 & 0.0004 & -0.0036 & -0.0048 & & & $a$ & & 0.97 \\
\hline & 1.3 & -0.03 & 0.35 & 0.31 & & & & & & 8 & & 0.94 \\
\hline \multirow{4}{*}{$\mathrm{L}_{\mathrm{f}}$} & -76 & 76 & 0.85 & 18 & -1.2 & -0.0004 & -0.0586 & -0.0002 & -0.6230 & 0.0099 & -0.0016 & 0.99 \\
\hline & -82 & 77 & 1.40 & 18 & -1.22 & -0.0004 & -0.059 & -0.05 & -0.64 & -0.0094 & & 0.99 \\
\hline & 147 & 58 & 0.58 & 11 & -1.22 & -0.0004 & -0.06 & & 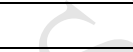 & & & 0.93 \\
\hline & 328 & 29 & 0.58 & 7 & & & & & & & & 0.90 \\
\hline
\end{tabular}




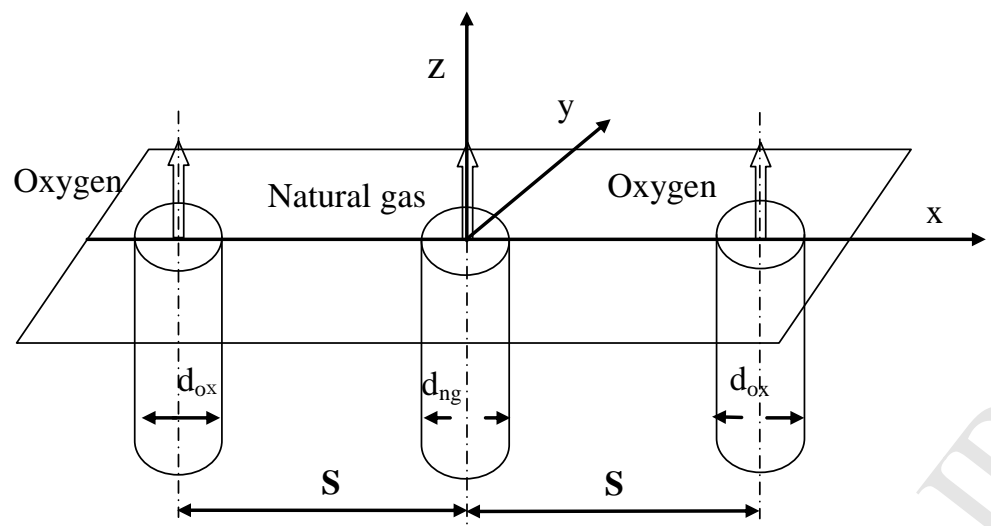

Fig. 1. Schematic diagram of separated-jet burner. 


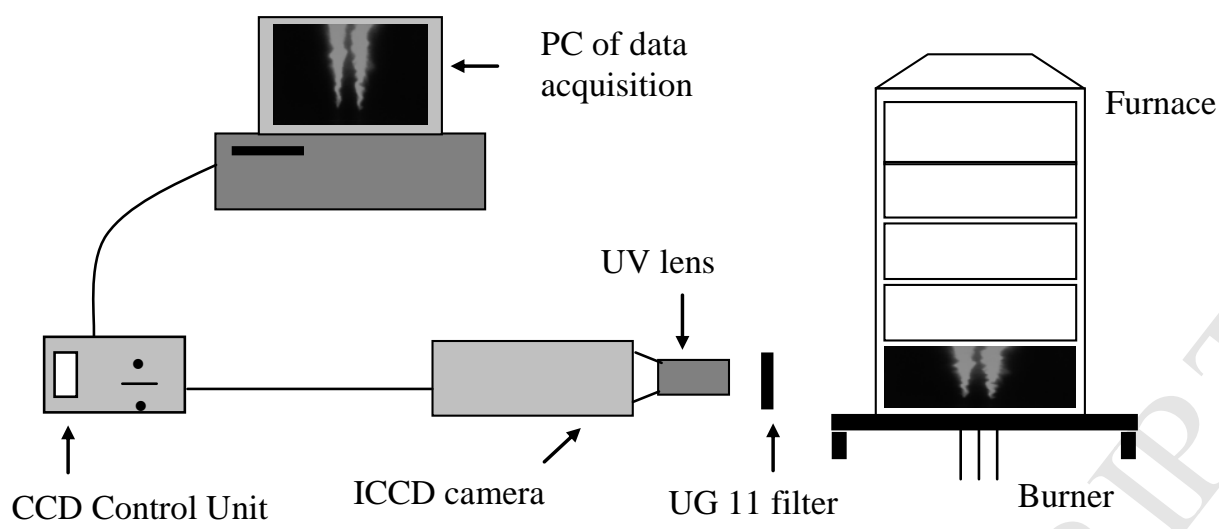

Fig. 2. Schematic diagram of the Chemiluminescence setup. 


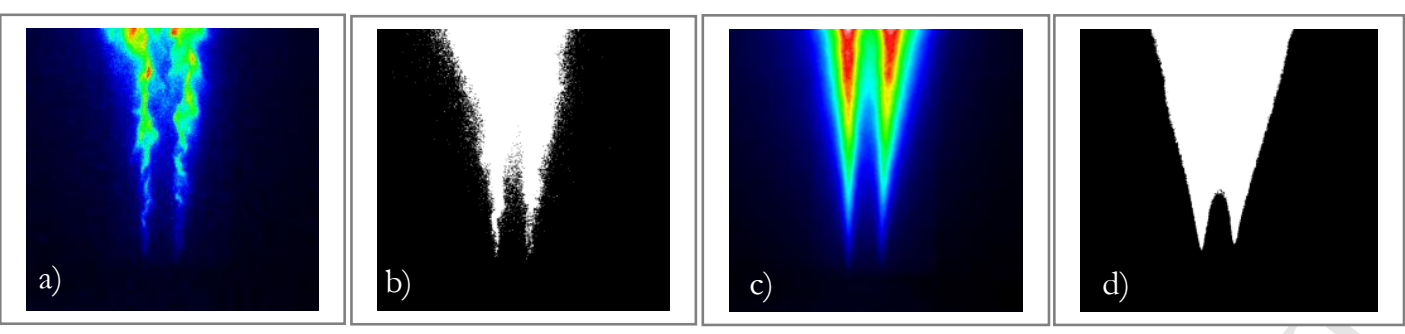

Fig. 3. Example of image processing of the lift-off zone of a flame issued from an oxy-fuel burner with separated jets. (a) Instantaneous image, (b) binarized image, (c) the average image of 400 instantaneous images, and (c) the average image of binarized images. 


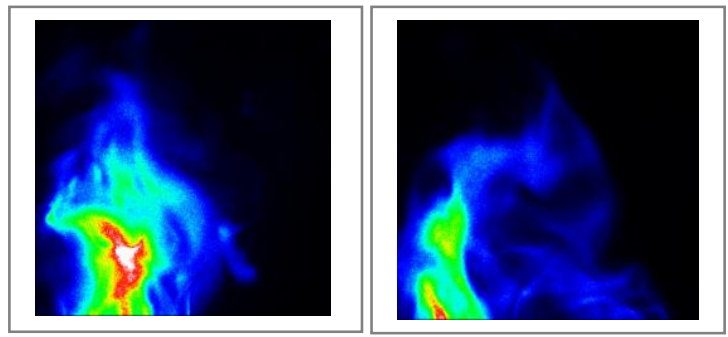

(a)

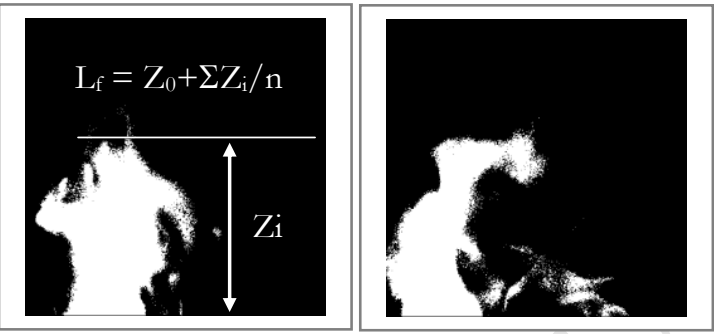

(b)

Fig. 4. (a) Examples of $\mathrm{OH}$ instantaneous images at the flame top and (b) their corresponding binarized image. 


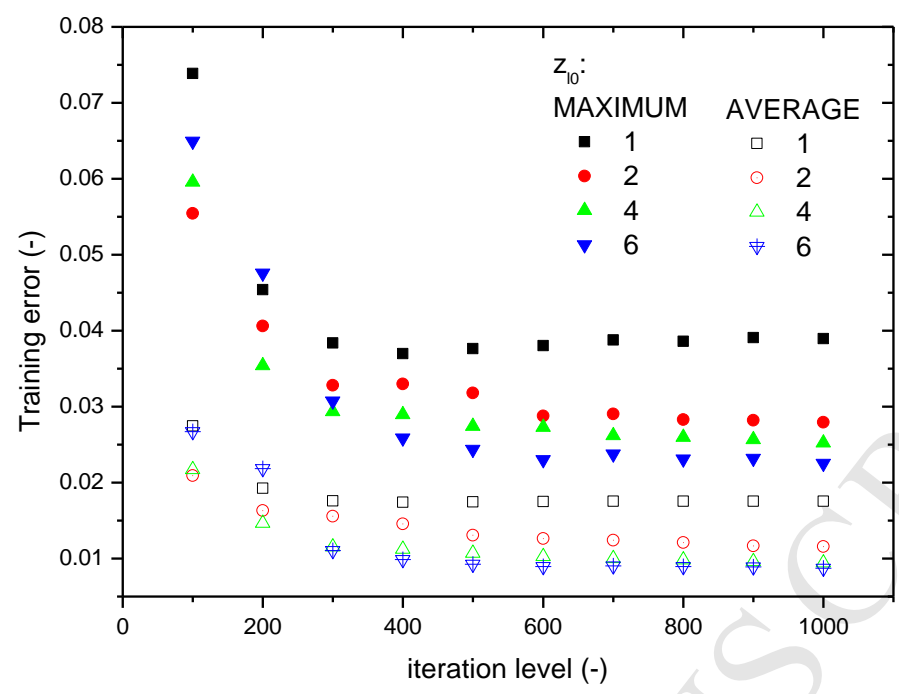

(a)

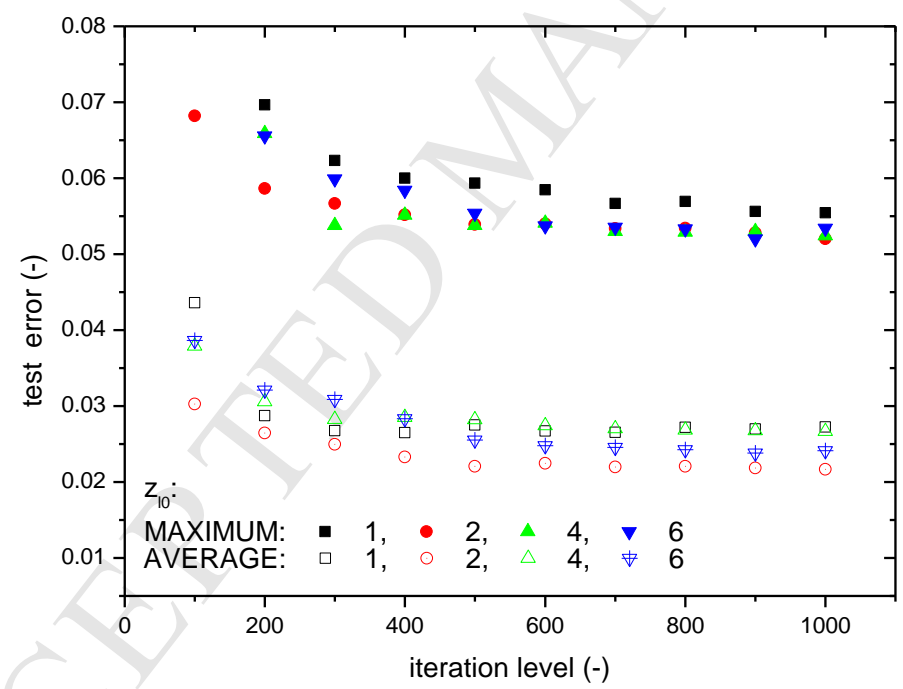

(b)

Fig. 5. Evolution of the average and maximum convergence criteria as function of iteration level for an increasing number of neurons in the hidden layer. Runs are performed in the case of $\mathrm{Z}_{\mathrm{lo}}$ output - training database $70 \%$. 


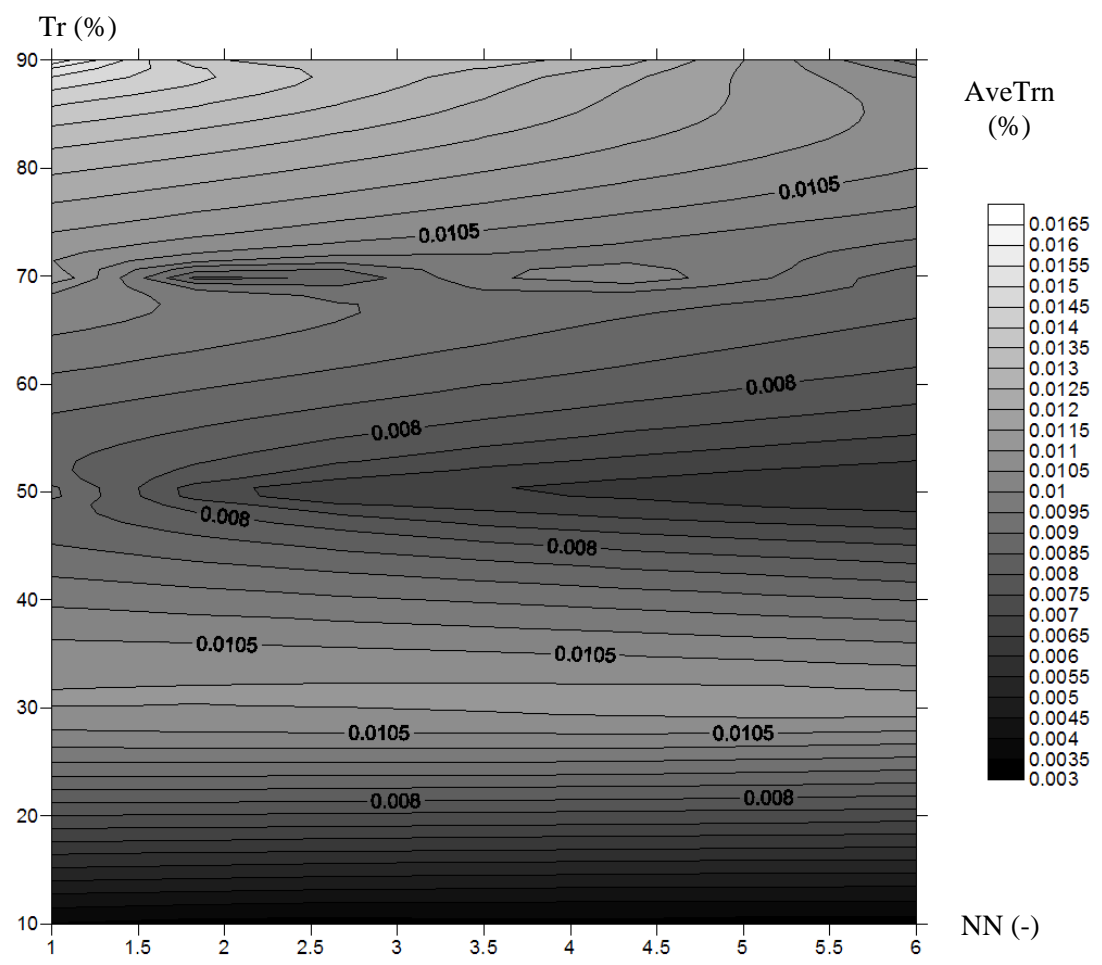

(a)

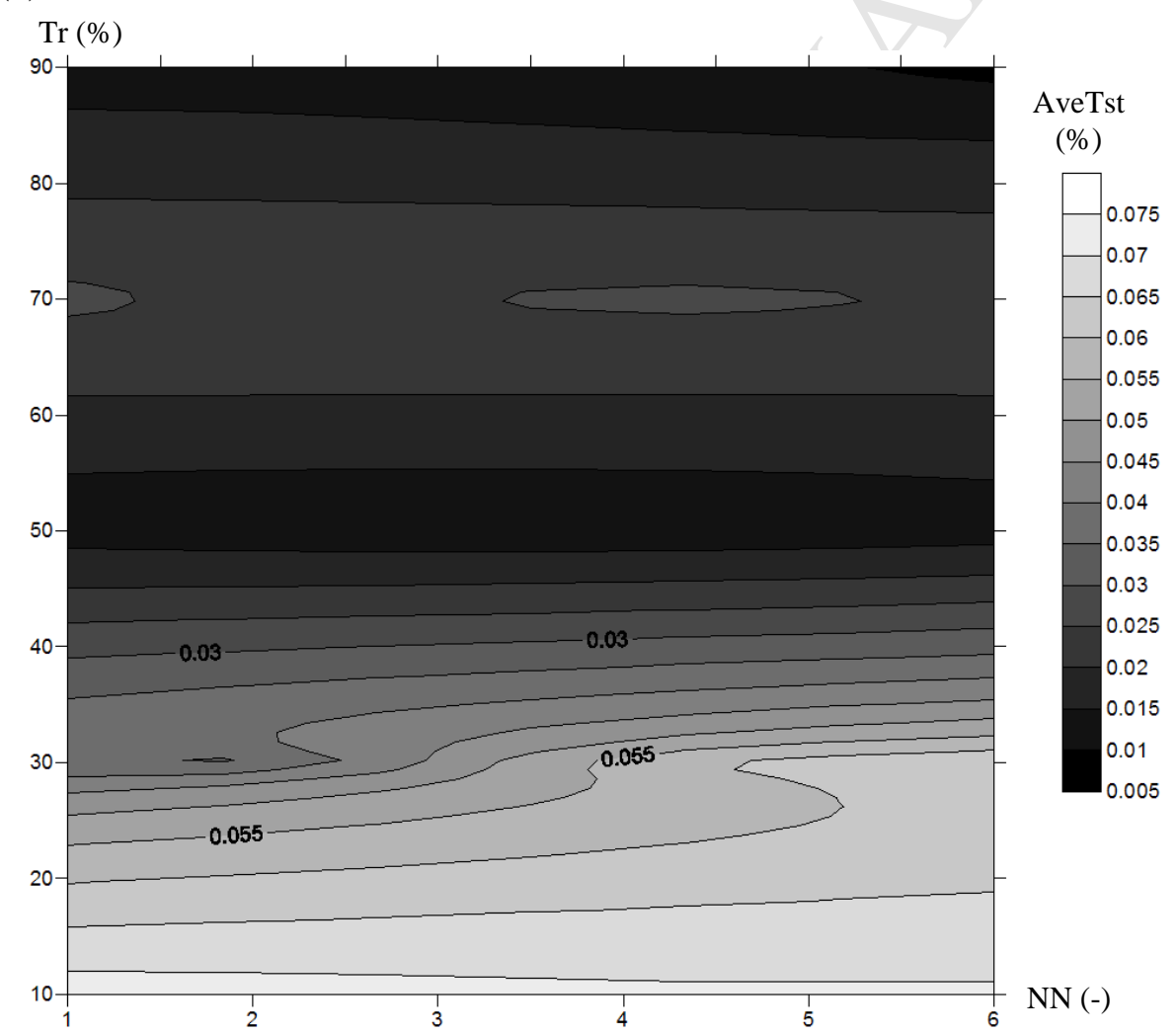

(b)

Fig. 6. (a) training and (b) test error maps relative to the output $\mathrm{Z}_{\mathrm{lo}}$ as function of neuron number and ratio from the whole database of samples used for training. 


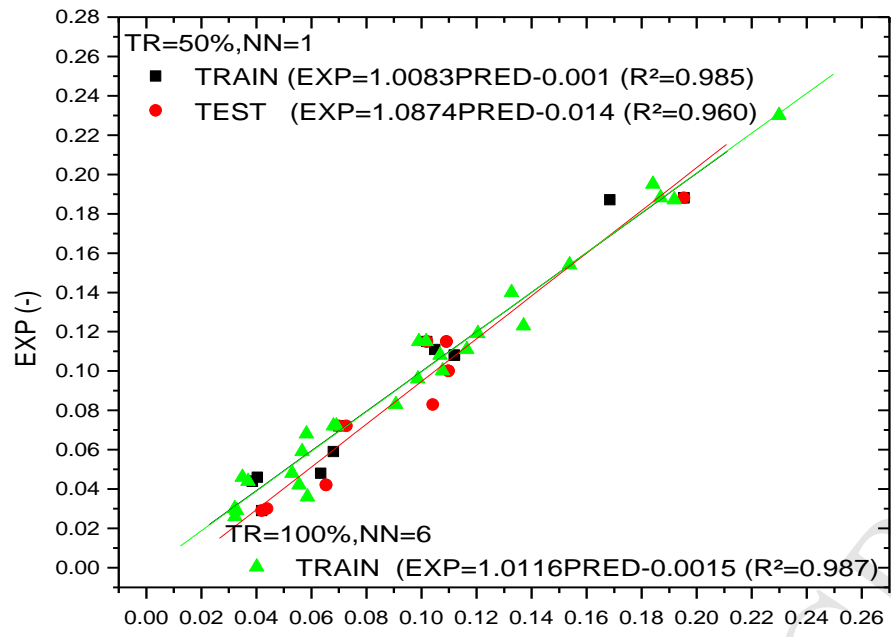

PRED(-)

Fig. 7. Comparing experimental and predicted $Z_{\mathrm{lo}}$ for two neural nets (optimal condition $\mathrm{NN}=1, \mathrm{TR}=50 \%$ and none-optimised condition $\mathrm{NN}=6, \mathrm{TR}=100 \%$ ). 


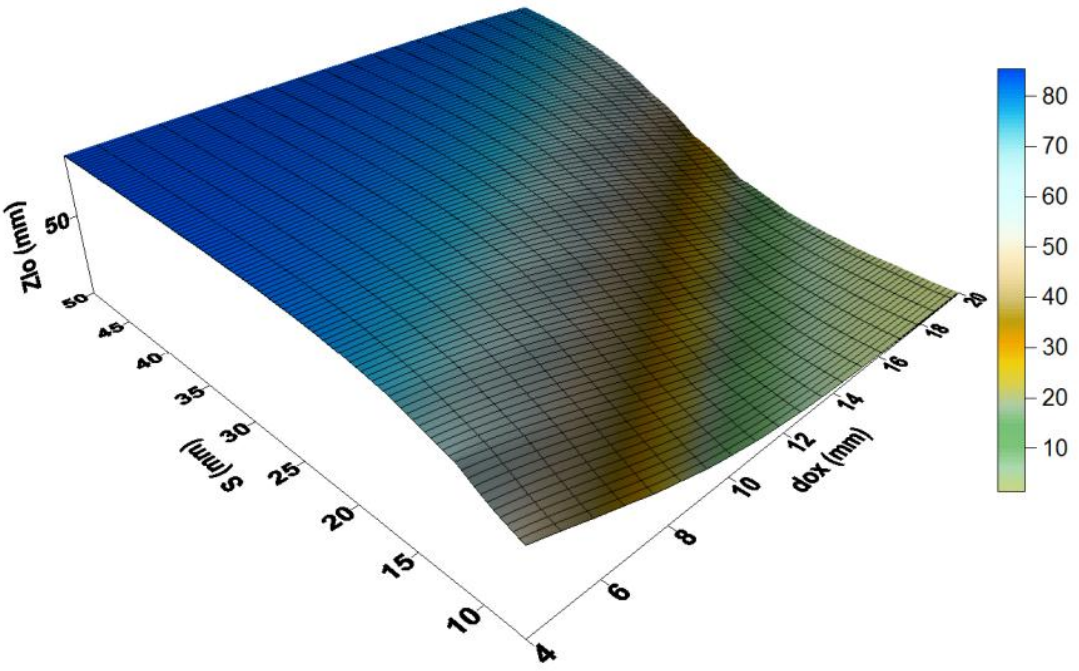

(a)

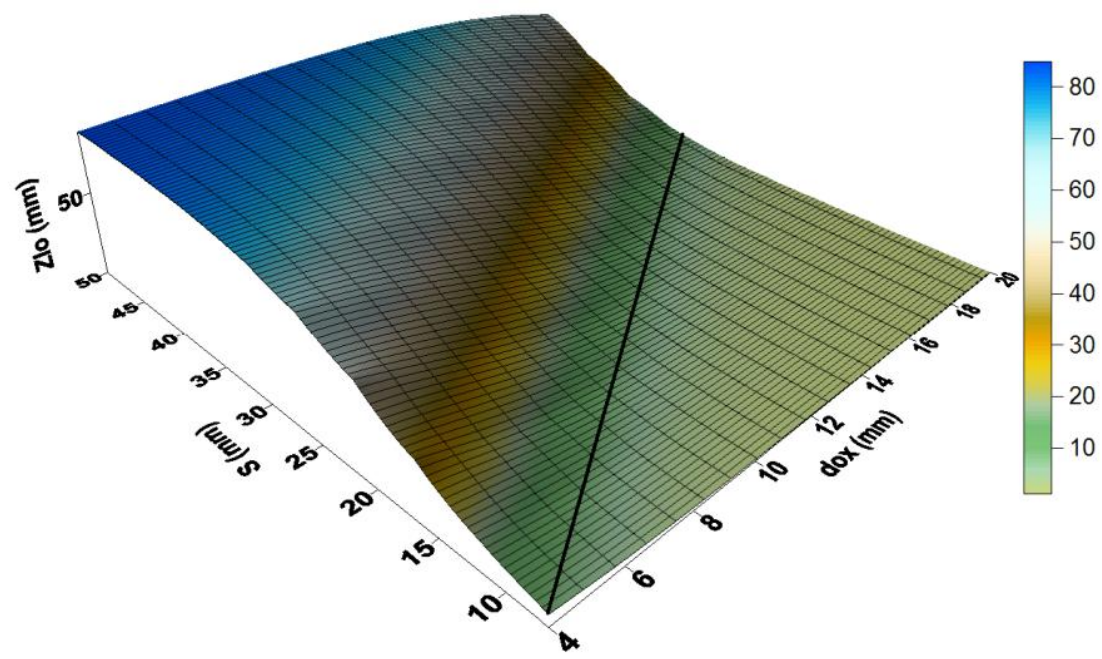

(b)

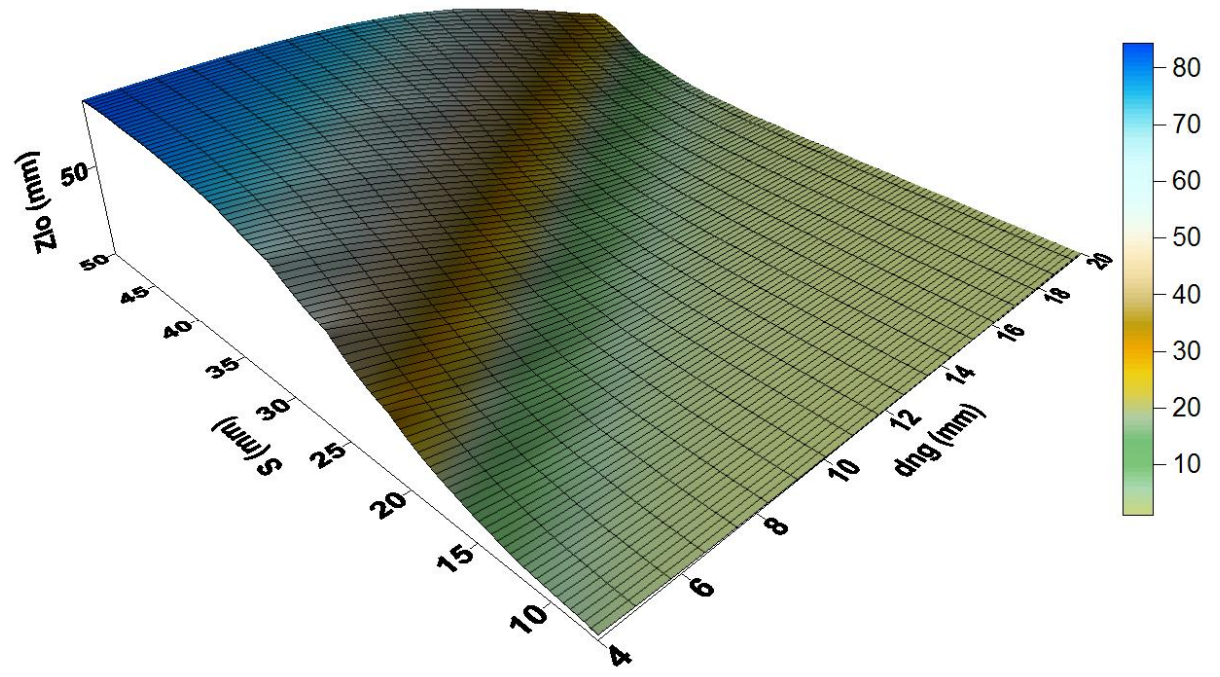

(c)

Fig. 8. Predicted maps of $Z_{10}$ as function of studied parameters. (a) $d_{n g}=4$, (b) $d_{n g}=11$, (c) $\mathrm{d}_{\mathrm{ox}}=15$. 


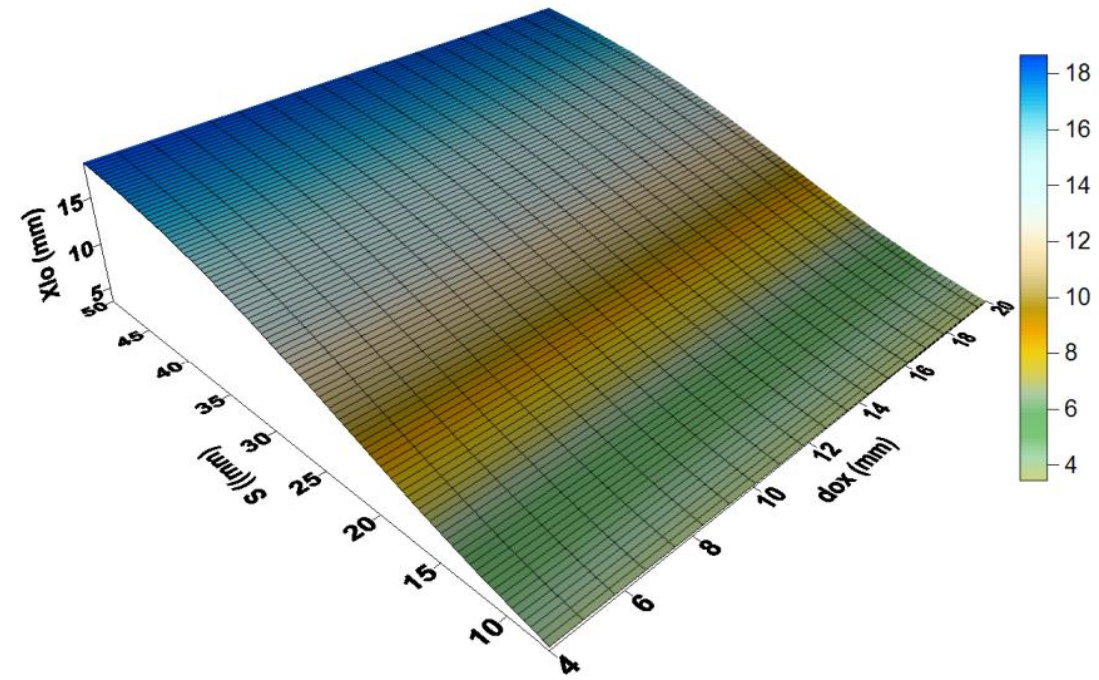

(a)

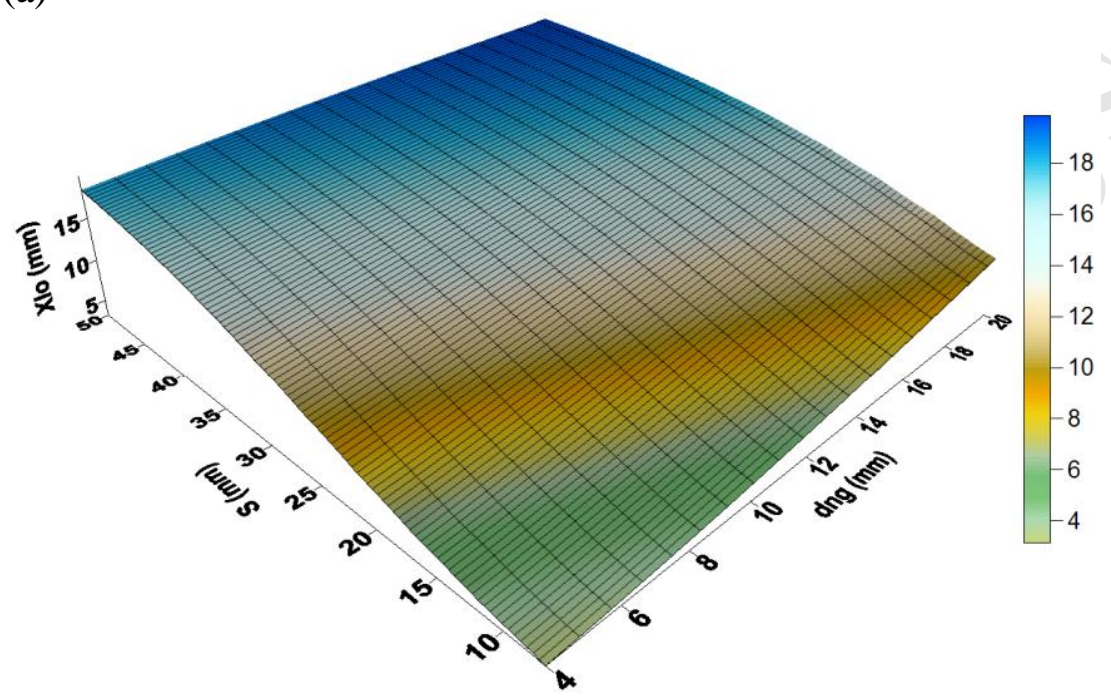

(b)

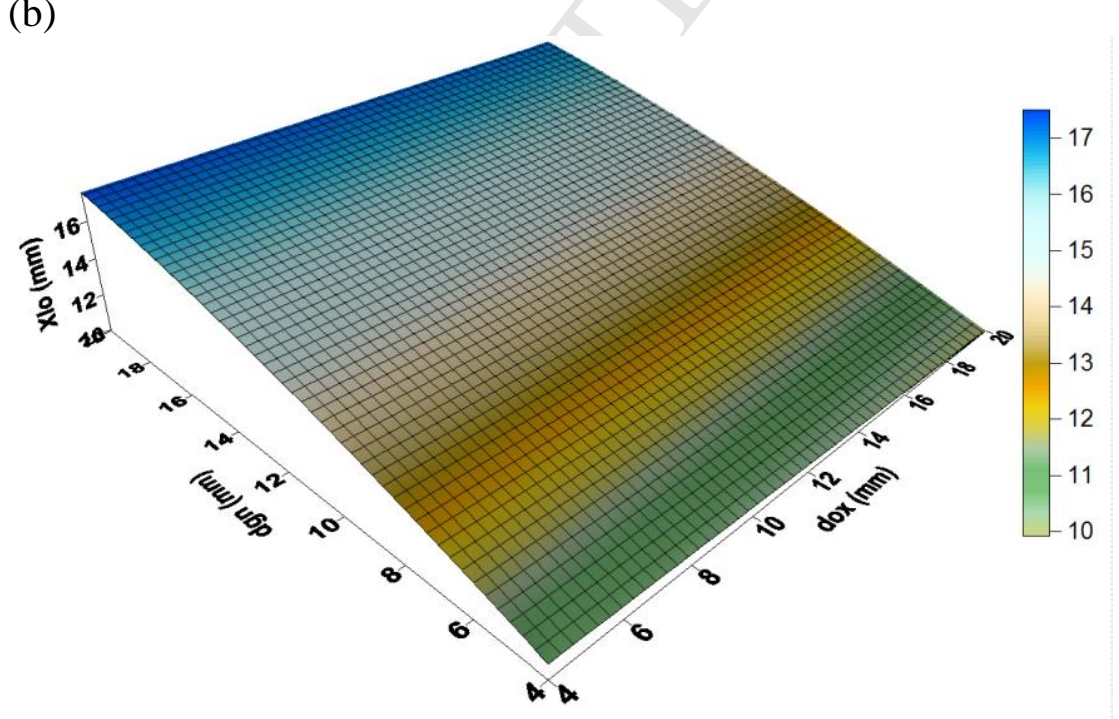

(c)

Fig. 9. Predicted maps of $X_{1 o}$ as function of studied parameters (a) $d_{n g}=5.8$, (b) $d_{o x}=13$, (c) $\mathrm{S}=26$. 


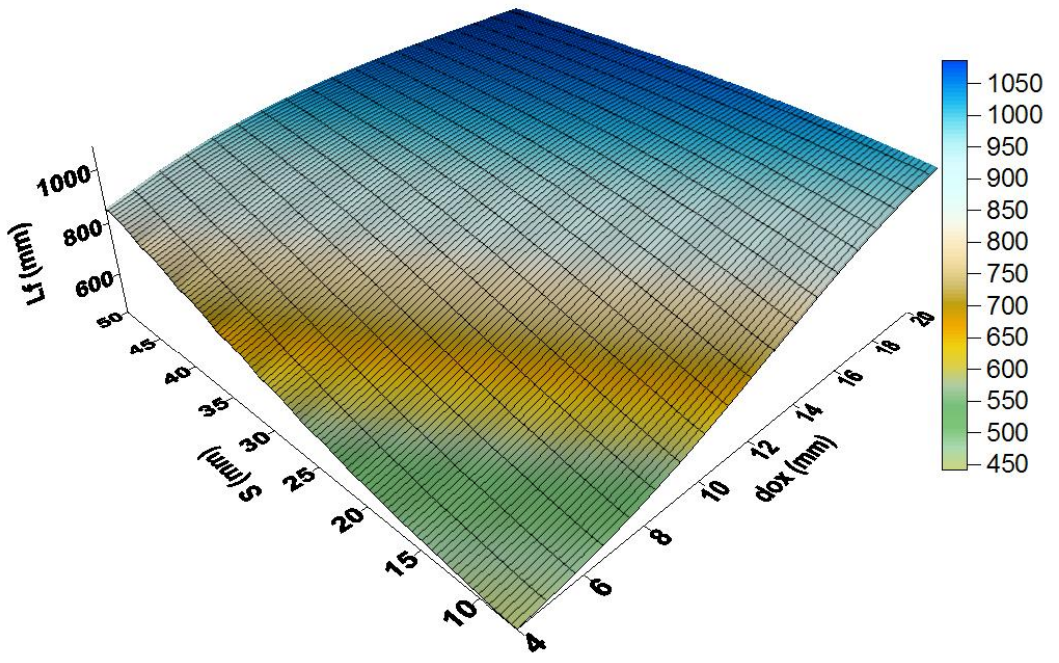

(a)

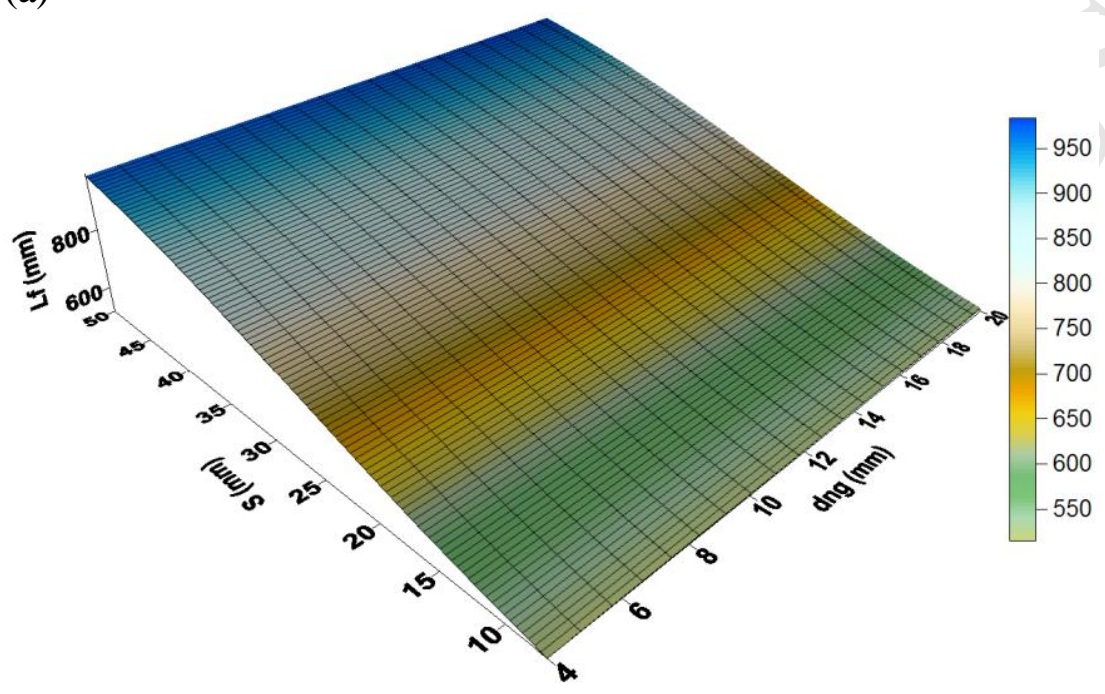

(b)

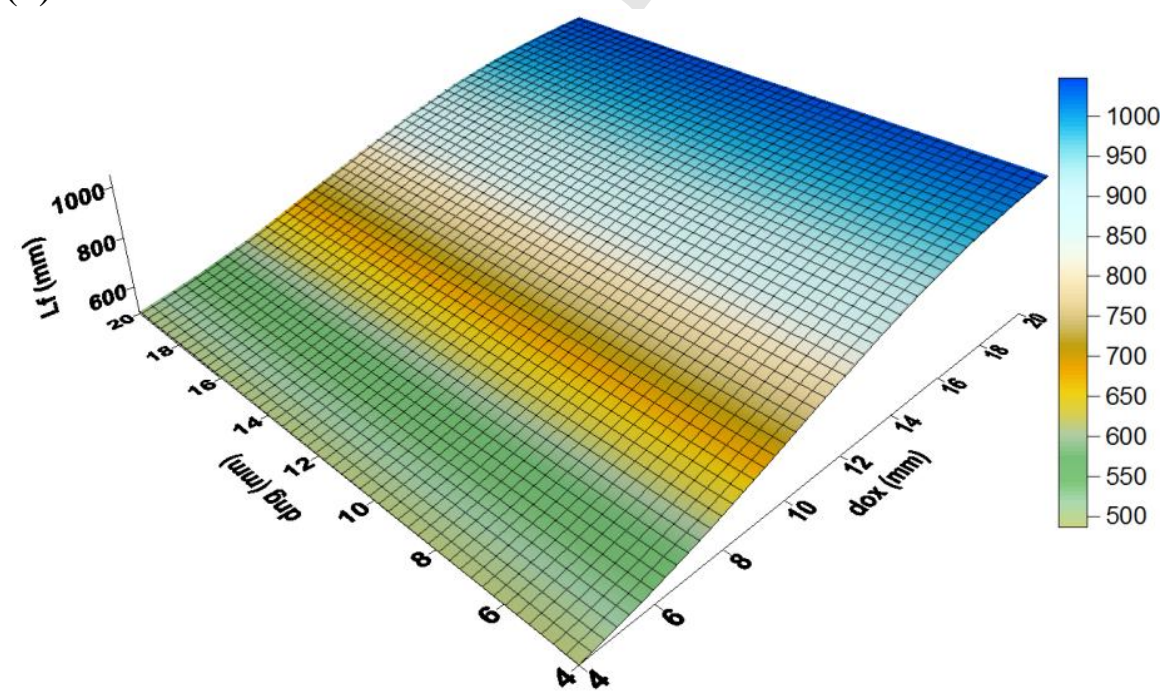

(c)

Fig. 10. Predicted maps of $\mathrm{L}_{\mathrm{f}}$ as function of studied parameters. (a) $\mathrm{d}_{\mathrm{ng}}=5.8$, (b) $\mathrm{d}_{\mathrm{ox}}=8$, (c) $\mathrm{S}=17$. 


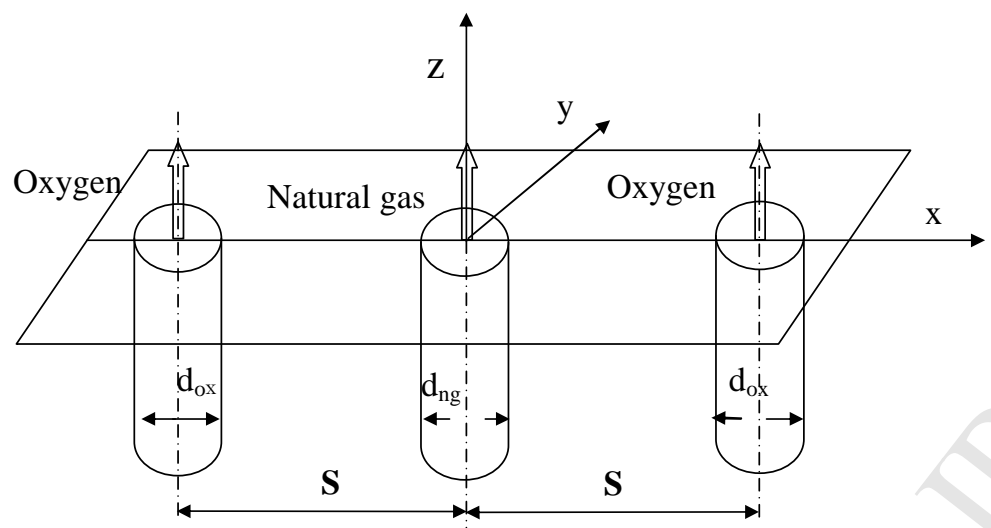

Fig. 1. Schematic diagram of separated-jet burner. 


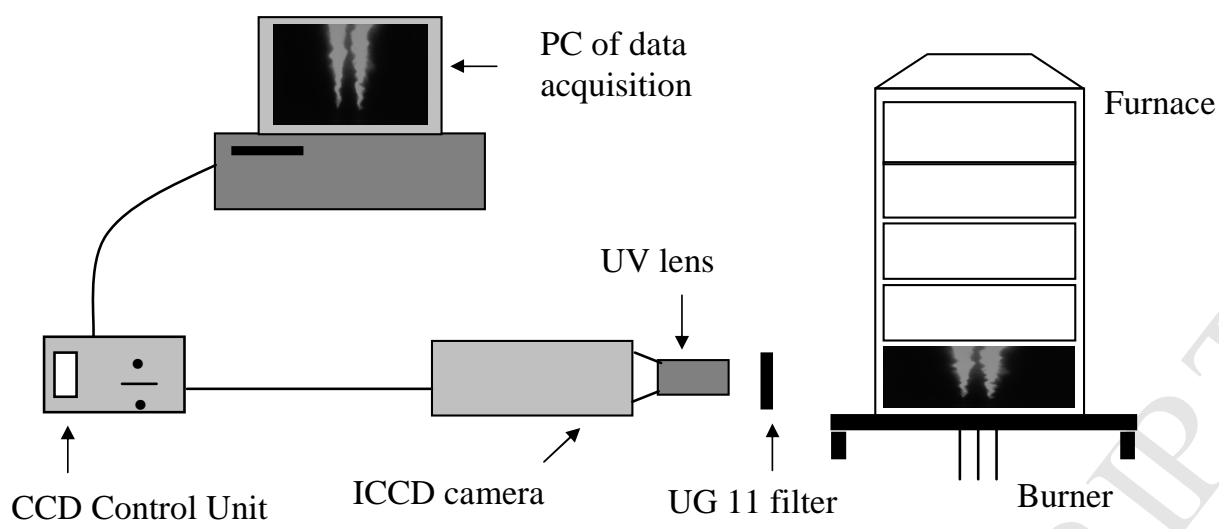

Fig. 2. Schematic diagram of the Chemiluminescence setup. 


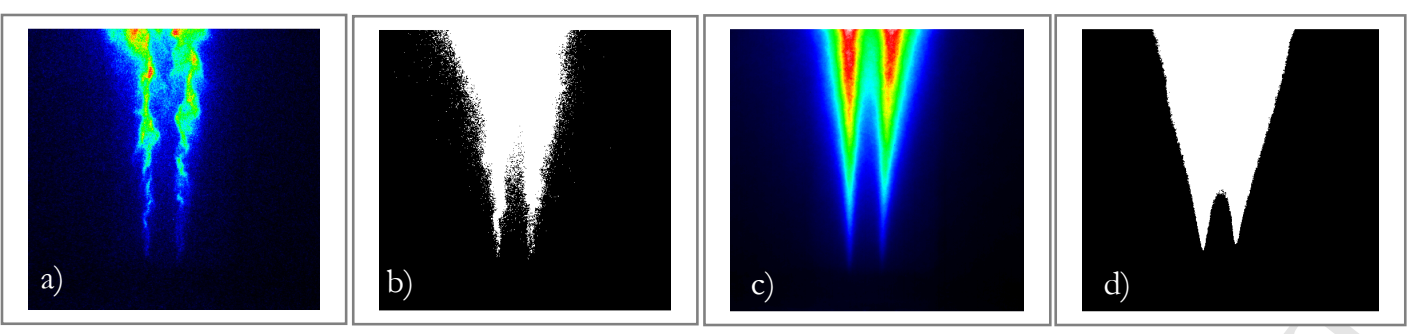

Fig. 3. Example of image processing of the lift-off zone of a flame issued from an oxy-fuel burner with separated jets. (a) Instantaneous image, (b) binarized image, (c) the average image of 400 instantaneous images, and (c) the average image of binarized images. 


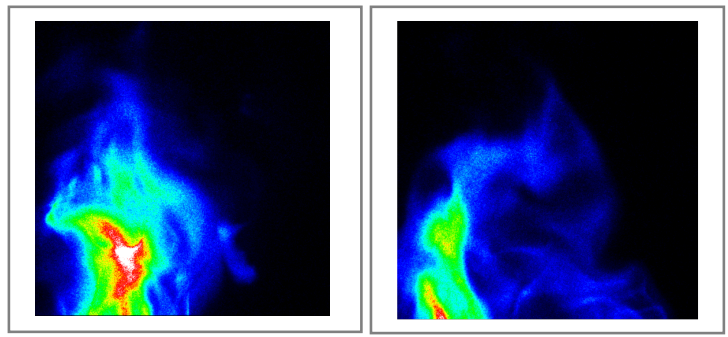

(a)

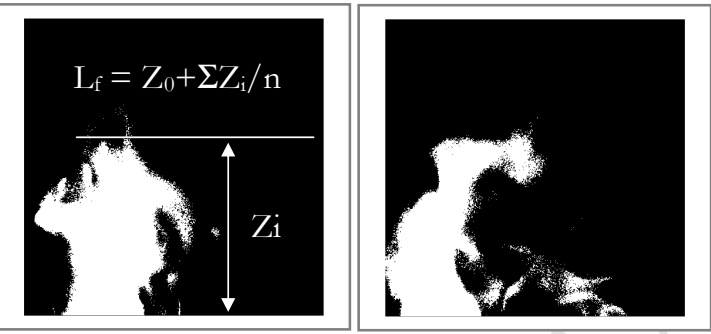

(b)

Fig. 4. (a) Examples of $\mathrm{OH}$ instantaneous images at the flame top and (b) their corresponding binarized image. 


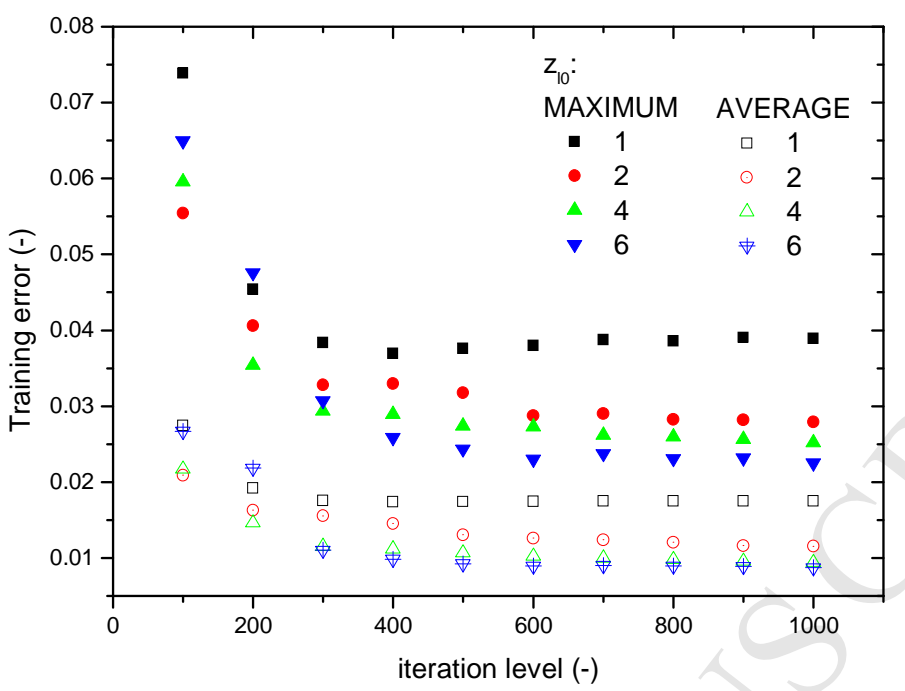

(a)

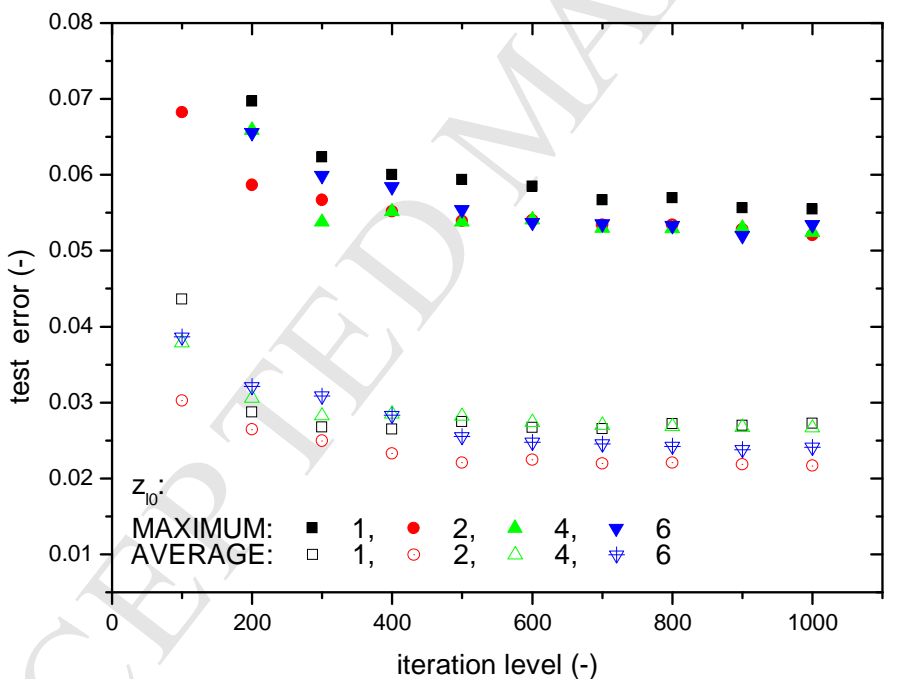

(b)

Fig. 5. Evolution of the average and maximum convergence criteria as function of iteration level for an increasing number of neurons in the hidden layer. Runs are performed in the case of $\mathrm{Z}_{\mathrm{lo}}$ output - training database $70 \%$. 


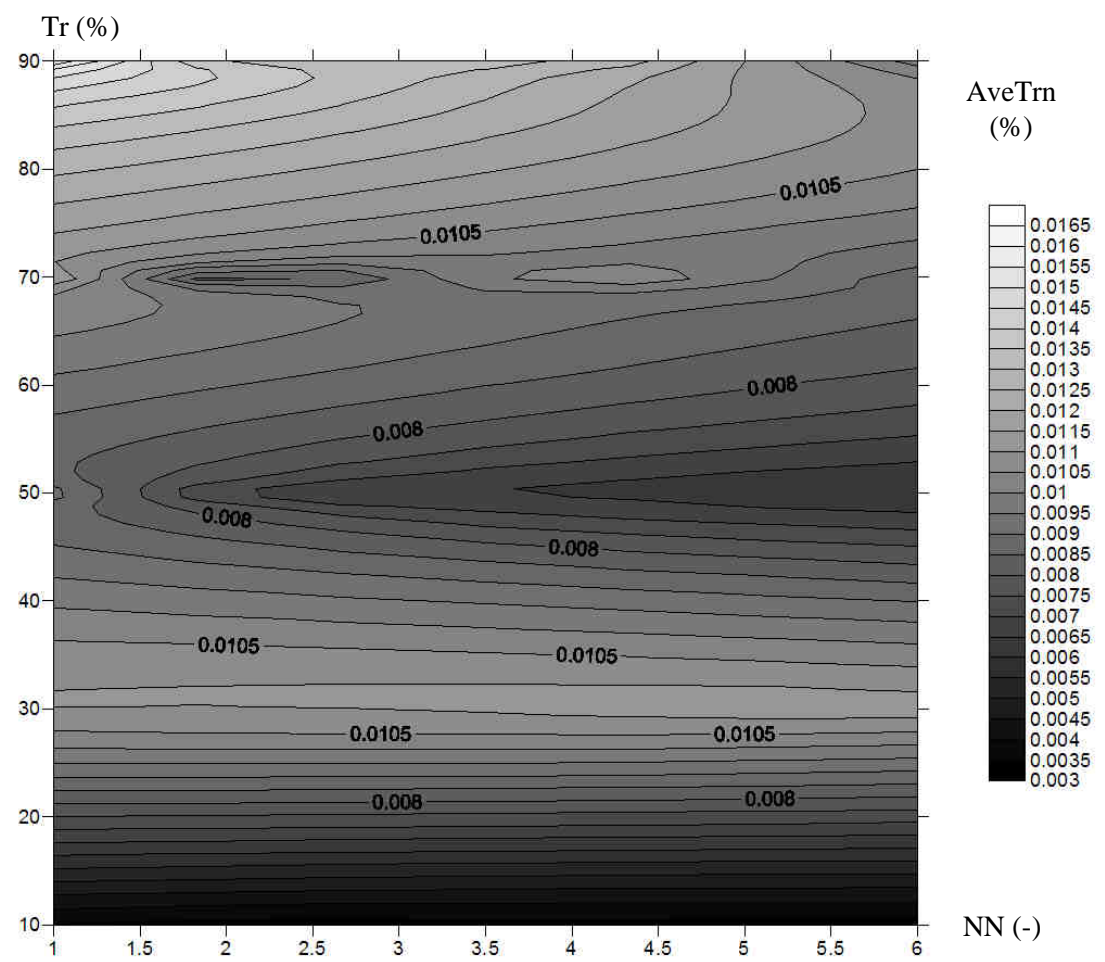

(a)

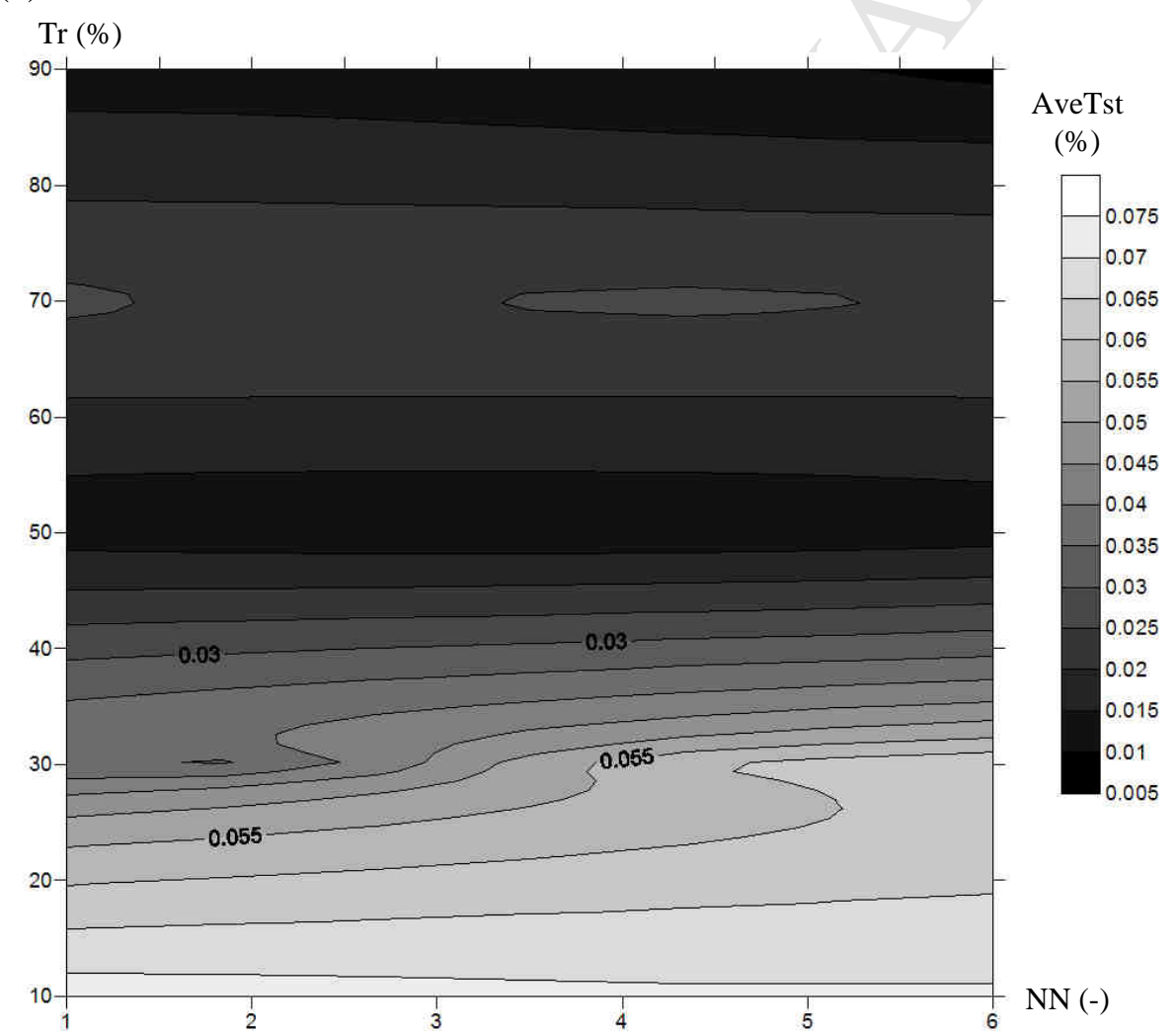

(b)

Fig. 6. (a) training and (b) test error maps relative to the output $\mathrm{Z}_{\mathrm{lo}}$ as function of neuron number and ratio from the whole database of samples used for training. 


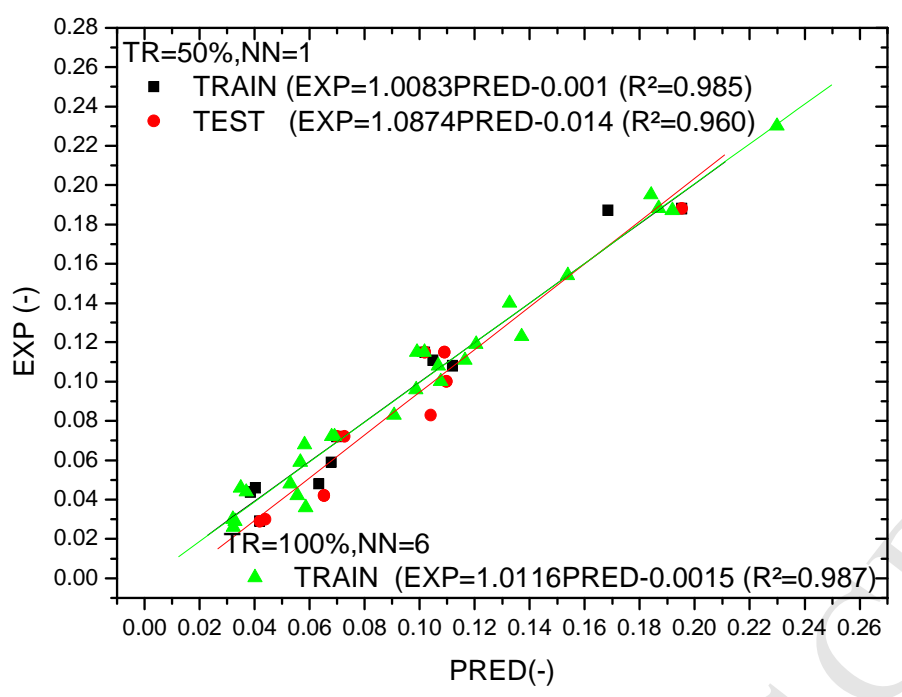

Fig. 7. Comparing experimental and predicted $Z_{\mathrm{lo}}$ for two neural nets (optimal condition $\mathrm{NN}=1, \mathrm{TR}=50 \%$ and none-optimised condition $\mathrm{NN}=6, \mathrm{TR}=100 \%$ ). 


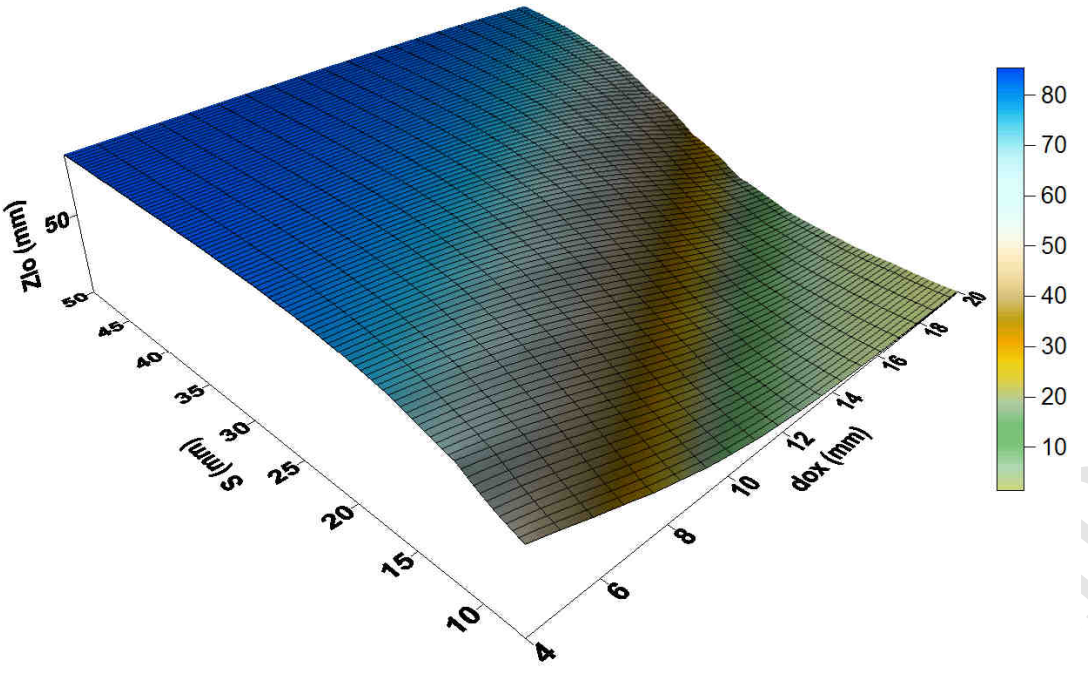

(a)

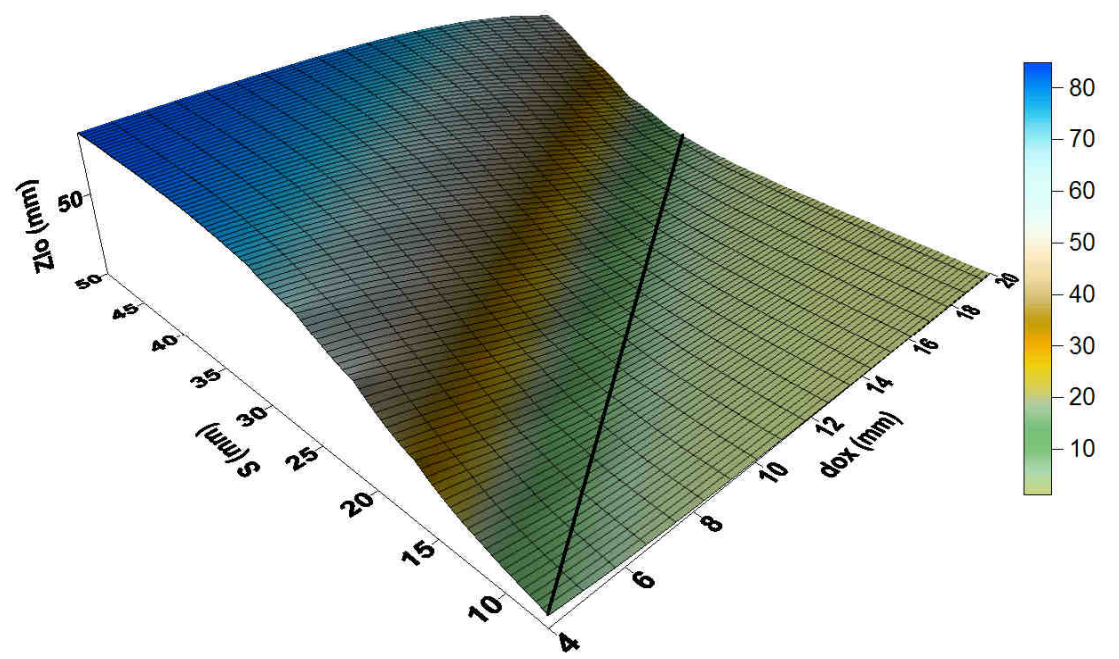

(b)

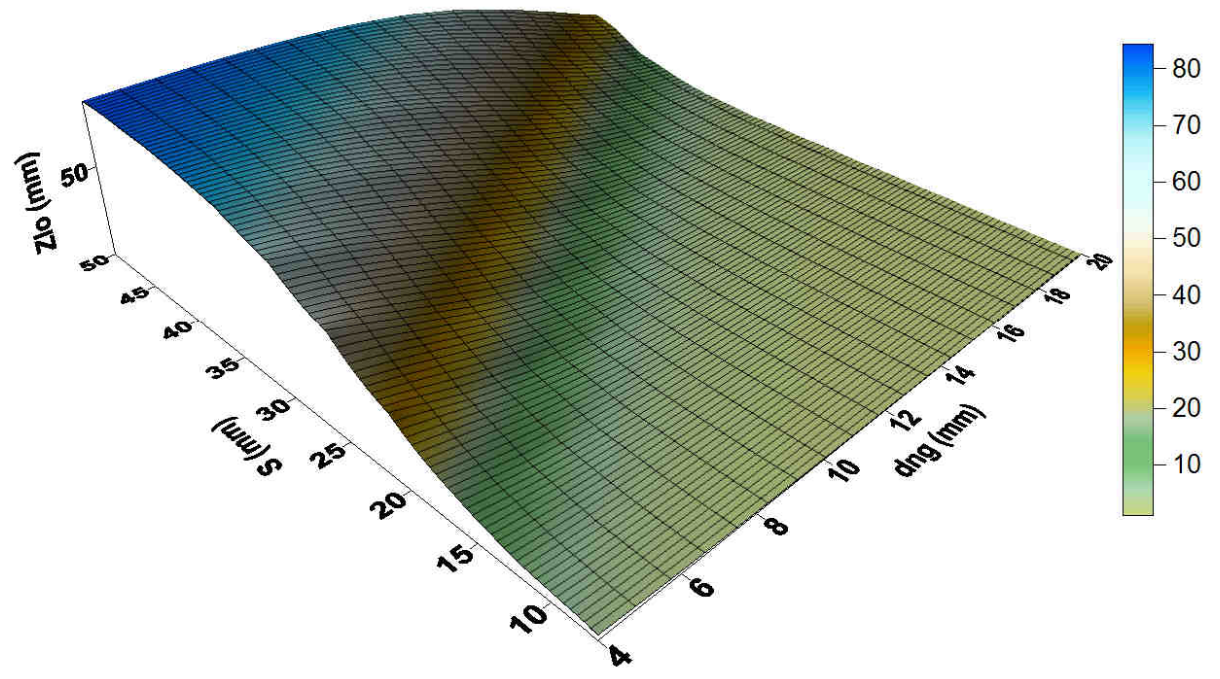

(c)

Fig. 8. Predicted maps of $Z_{\mathrm{lo}}$ as function of studied parameters. (a) $d_{n g}=4$, (b) $d_{n g}=11$, (c) $\mathrm{d}_{\mathrm{ox}}=15$. 


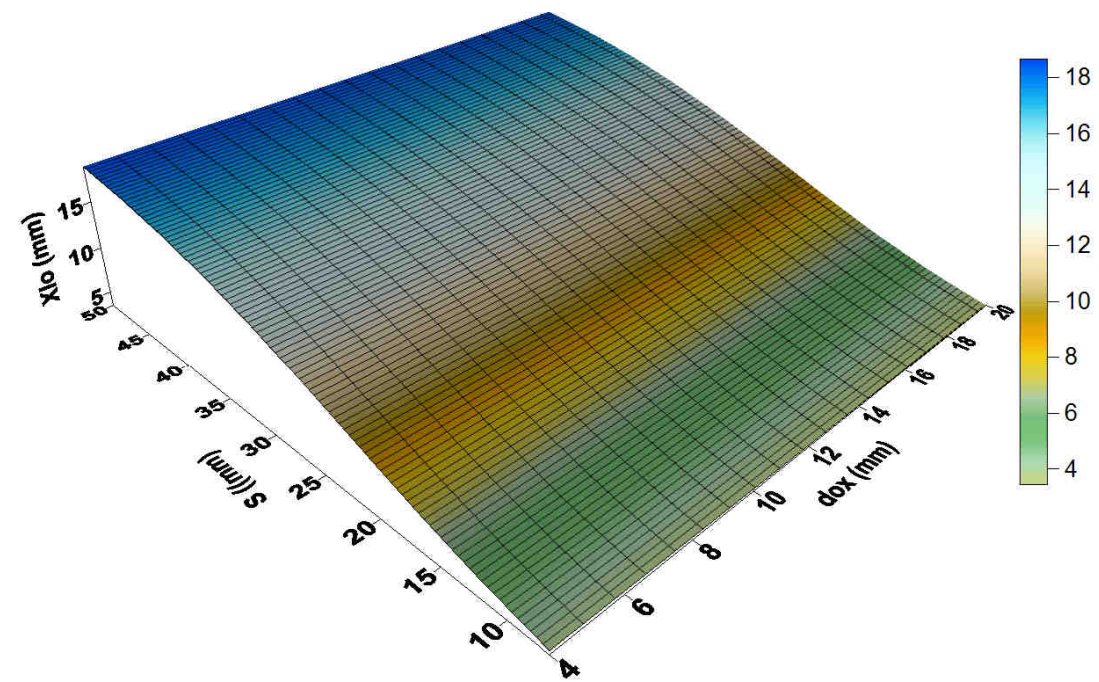

(a)

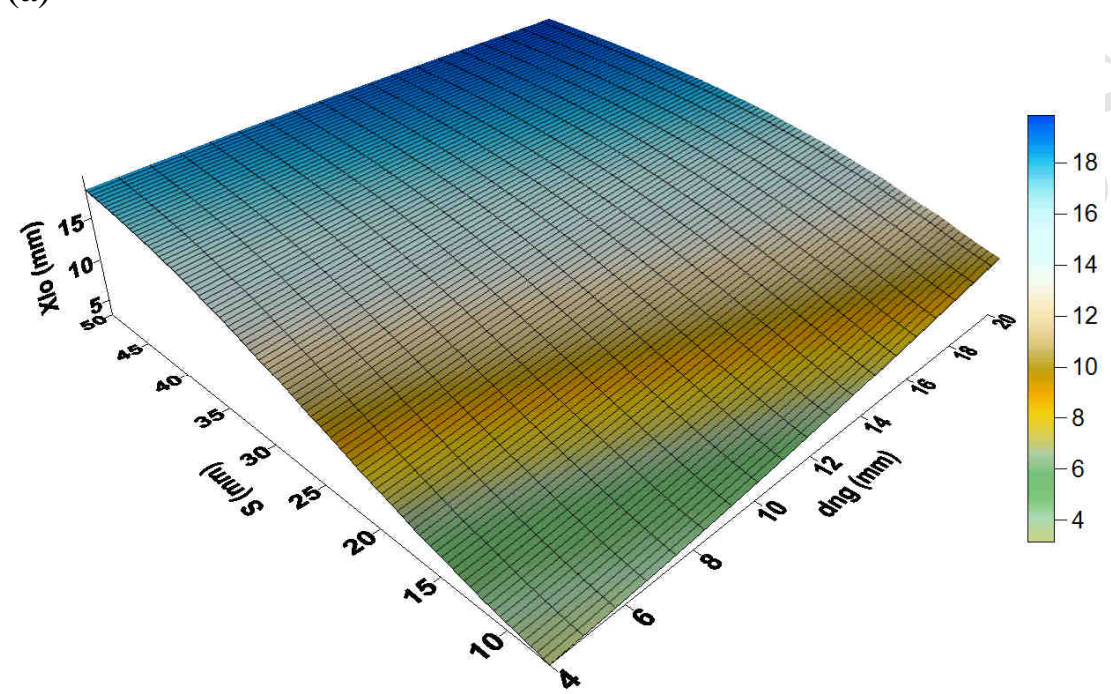

(b)

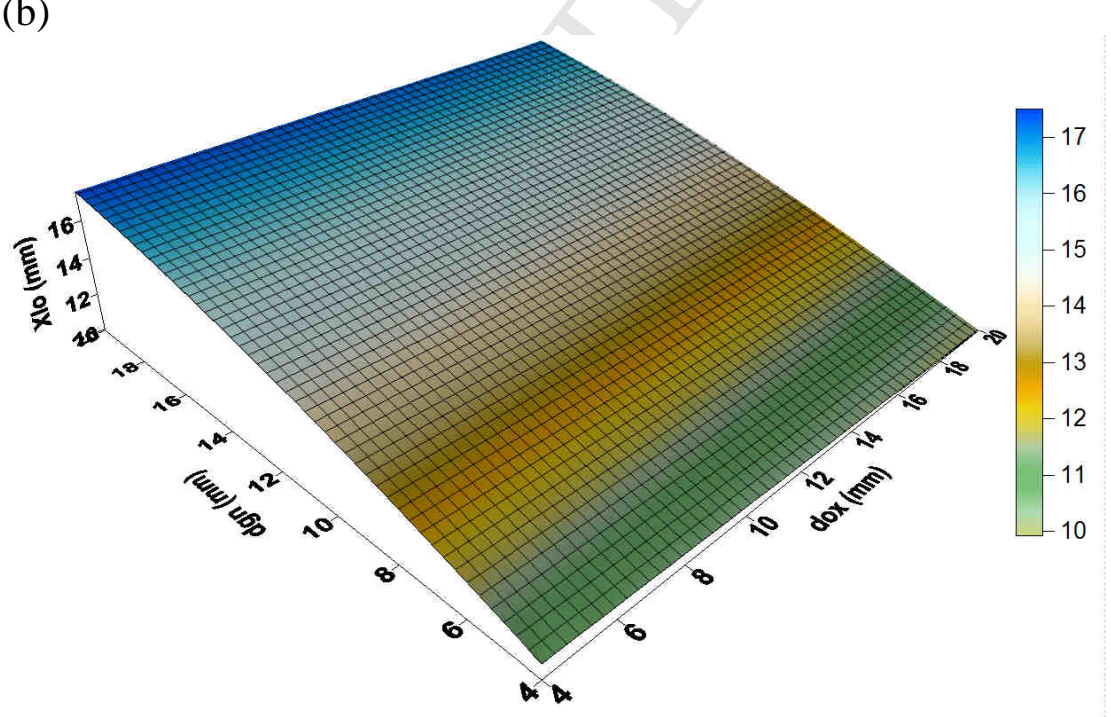

(c)

Fig. 9. Predicted maps of $X_{1 o}$ as function of studied parameters (a) $d_{n g}=5.8$, (b) $d_{o x}=13$, (c) $\mathrm{S}=26$. 


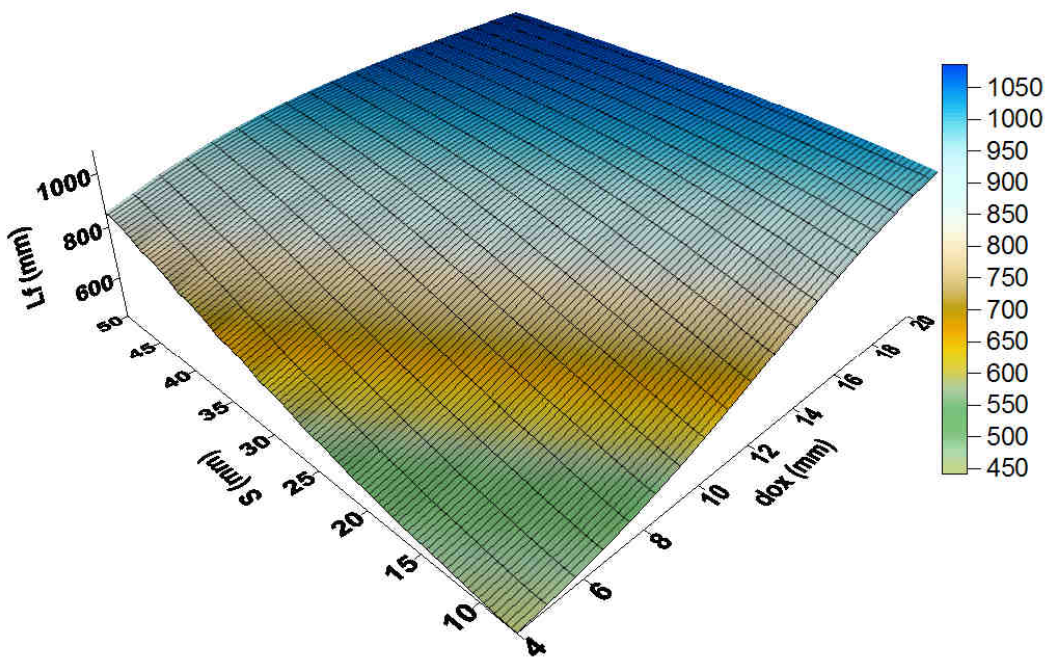

(a)

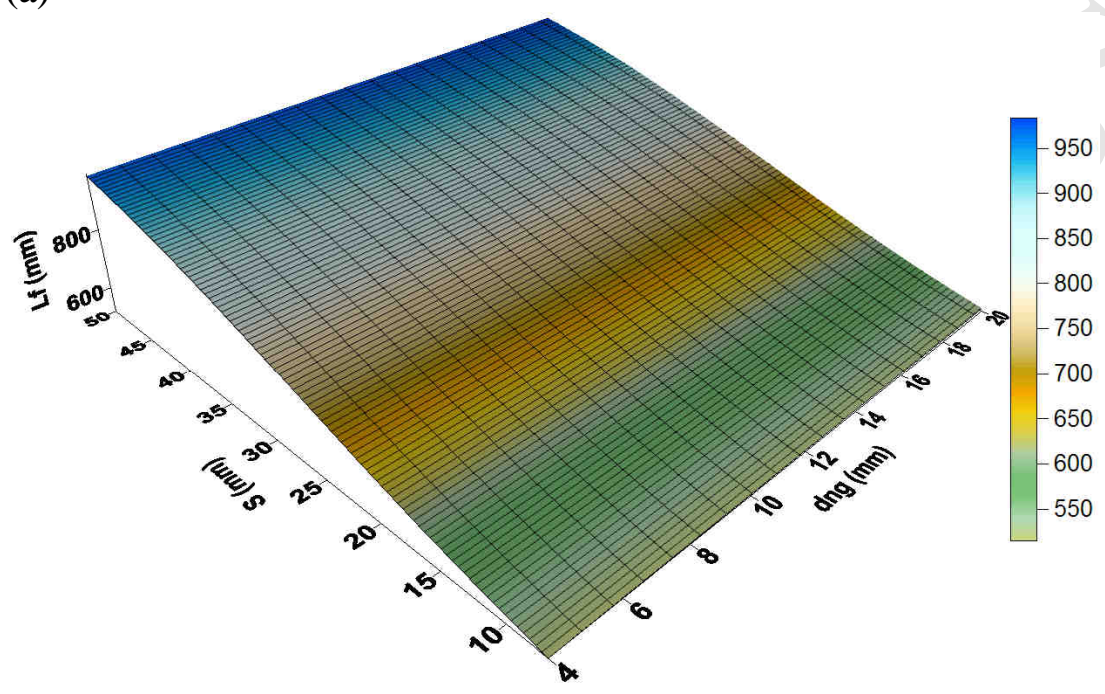

(b)

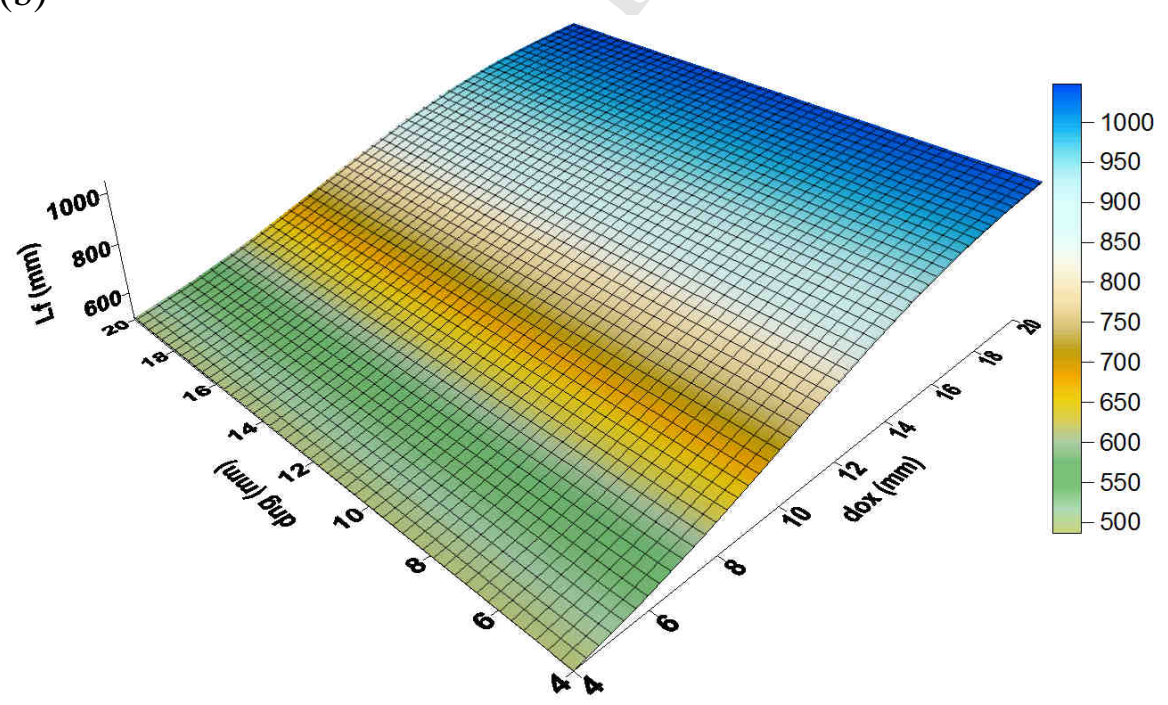

(c)

Fig. 10. Predicted maps of $\mathrm{L}_{\mathrm{f}}$ as function of studied parameters. (a) $\mathrm{d}_{\mathrm{ng}}=5.8$, (b) $\mathrm{d}_{\mathrm{ox}}=8$, (c) $\mathrm{S}=17$. 